Essay

\title{
Ecological Econophysics for Degrowth
}

\section{Salvador Pueyo}

Institut Català de Ciències del Clima (IC3), C/ Doctor Trueta 203, 08005 Barcelona, Catalonia, Spain; E-Mail: spueyo@ub.edu; Tel.: +34-935-67-99-77; Fax: +34-933-09-76-00

Received: 17 February 2014; in revised form: 22 April 2014 / Accepted: 19 May 2014 /

Published: 28 May 2014

\begin{abstract}
This paper outlines a synthesis of ecological economics with econophysics and other complexity approaches to economics. Arguably, the resulting "ecological econophysics" will be scientifically sounder than mainstream economics and much better suited to addressing a major challenge of our times: the development of democratically-based policies to reduce economic throughput to an environmentally sustainable level without triggering economic crises and without excluding part of the world's population, i.e., to implement degrowth. Degrowth will need major structural changes, which leads us to question whether there are limits to the malleability of the economic system's architecture. A fundamental limit will be encountered if, as suggested by the physics of complexity, long-lasting complex systems always occur midway between an ordered and a disordered state. There is much evidence that this hypothesis holds and that the current economic system satisfies this condition. However, this does not mean that the problems posed by this system should be unavoidable. Ecological econophysics gives clues to identifying alternative economic systems that would also function between order and chaos, but which would have radically different implications for environmental sustainability and social justice.
\end{abstract}

Keywords: complex systems; theoretical ecology; edge of chaos; self-organized criticality; chaordic; peak oil; climate change; recessions; equality; degrowth

\section{Introduction}

Mainstream economics sustains a curious position about relaxation times. In the language of physics, relaxation time $\tau$ is a measure of the time needed by a system to reach equilibrium ("equilibrium" in a broad sense, not necessarily thermodynamic equilibrium). Mainstream economics assumes $\tau \rightarrow 0$ for 
internal adjustments of the economic system (hence, the standard use of general equilibrium models, which imply, for example, the impossibility of endogenous crises). The other extreme $(\tau \rightarrow \infty)$ is often assumed in regard to the mutual adjustment between the system and its environment: key nonrenewable resources are never depleted (alternatively, depletion is considered possible but inconsequential), while climate change and other forms of environmental degradation never reach levels at which they interfere seriously with economic activity. Neither assumption has an empirical basis, and both have been defied. Ecological economists [1], based on scientific results, generally sustain that the environmental feedback on the economic system is already apparent and could well become dramatic in the near future (they replace the aprioristic belief of $\tau \rightarrow \infty$ by a set of finite $\tau$, uncertain but scientifically based and, often, small enough to be policy-relevant). The internal equilibrium assumption $(\tau \rightarrow 0)$ has been someway relaxed by several economic schools, but it has been most thoroughly debunked by a recently developed discipline known as econophysics [2-5]. Econophysics is quickly expanding in the pages of physics journals and consists of the application of concepts and tools of statistical physics to economics.

A more scientific economics should consider all relevant time scales and the interactions among them. This will result from a synthesis of ecological economics, econophysics and other related disciplines, which could be named "ecological econophysics". The present paper explores some key topics for the development of an ecological econophysics.

The motivation for this research is not purely academic: ecological econophysics is envisaged as the science that can give a solid foundation to policies that combine the awareness of environmental limits to growth with the wish for social justice. The interest in policies along these lines has a long history [6-8] and has recently gained momentum under the label of "degrowth" [9-12] (while this is mostly a northern movement, similar ideas have emerged in the political South [13-15]). Degrowth proponents pursue the democratic implementation of policies, combined with volunteer practices, to reduce economic throughput to sustainable levels in a particular manner: smooth and equalizing (with the steepest descent for the highest income people and countries, while everybody is warranted an acceptable level of consumption). The "throughput" to be reduced is, primarily, physical (i.e., quantified in terms of energy, matter and specific types of resources and emissions), but a key feature that distinguishes degrowth from other approaches to sustainability (such as "green growth") is its renouncing of the goal of increasing GDP (a position that is increasingly shared [16]). The possibility or not of decoupling GDP from physical throughput is a hotly debated issue, but there can be little doubt that the political imperative of increasing the first poses a serious obstacle to decreasing the later. Degrowth proponents take note of studies indicating that, after some given GDP per capita has been exceeded, further increases in GDP do not contribute significantly to psychological wellbeing [17-19]. It can be added that increasing GDP is an extremely inefficient way to reduce poverty, as shown in [20] and previously foreseen in [21].

A synthesis of ecological economics with econophysics and related disciplines will be more than the sum of its parts. For example, ecological economists might warn that it will not be physically possible to sustain the current throughput beyond some given point in time, but even though this situation results from an imbalance between the economic system and its environment, many crucial features of the ensuing decline will depend on the dynamics of imbalances within the economic system. The smooth, equalizing and democratically managed decline that defines degrowth is just one possibility. Others are collapse, a sequence of recessions, or the gradual exclusion to the death of an increasing fraction of the 
world's population while others remain affluent. Economic models are needed to study the plausibility of each of these patterns of decline as a function of different economic policies, but it is econophysical and not mainstream models that can play this role. Because of the equilibrium assumption, standard growth models [22] exclude a priori any type of change that is not smooth, such as collapse or recessions. Because they restrict their attention to a "representative agent", these models cannot inform us of the degree of equality. In contrast, since both economic fluctuations and resource distribution among agents can be described by statistical distributions, and statistical physics relates mechanisms to distributions, the application of statistical physics to economics (i.e., econophysics) is an optimum tool to identify the policies that will make degrowth possible (even though this is less straightforward, econophysics can even give clues on the degree to which the transition to sustainability can be managed democratically).

Physics has always played a key role in ecological economics. One of its founding works, Georgescu-Roegen's The Entropy Law and the Economic Process [23], framed the limits to growth in thermodynamic terms. In this case, physics was applied to its usual objects, such as energy and matter. The difference is that econophysicists borrow concepts and methods that are usually applied to sets of molecules and apply them to sets of economic agents and assets.

Econophysics can be considered a branch of "complexity science" or "complex systems theory". This is a transdisciplinary field with its main roots in physics (see, e.g., the popular account in [24]). Thanks to complexity science, physics moved beyond its traditional focus on extremely simple systems (e.g., balls or, for the case, rockets following a parabolic trajectory) and is applying its methods to more complex systems, which had been previously studied from other, complementary points of view, such as living beings, ecosystems, societies or the Earth system. Complexity scientists are especially interested in findings that are equally valid in several different fields. For example, in parts of the present paper, I discuss whether forest fires can help us to understand economic recessions. In fact, many works applying complex systems theory to economics do not use the label "econophysics" (e.g., [25]). Some do not use the "complexity" label either (e.g., [26]). Among the later, there are, for example, some attempts by theoretical ecologists to develop more robust banking networks based on lessons obtained from the study of ecosystems [27,28] applying concepts that, often, have their roots in physics. The "ecological econophysics" outlined in this paper not only considers results labeled as "econophysics", but also other complexity approaches to economics, especially the approach consisting of the generalization of ecological theory to economics. This paper stands on the previous literature on economic complexity, but differs from most of this in its ultimate motivation: while many contributions to economic complexity respond to purely academic interests, seeking ways to increase revenues at the stock market or are aimed at the stabilization of the current system with regard to crises, this paper is a step for the development of recipes to transform the system in favor of ecological sustainability, equity and democracy.

There are precedents of research at the interface between complex systems theory and ecological economics, whose motivations might be closer to the present paper's. Some entrances to different strands of literature are [29-41]. The ways complex systems theory has been used in these sources is remarkably diverse, ranging from the epistemological discussion on complexity as an argument for post-normal science [32] to computer simulations using complex agent-based models [36]. The current manuscript lies at an intermediate point in this range, being mostly heuristic but oriented to quantitative applications. 
It differs from many of these works because of its orientation to inform degrowth. Besides, a clear singularity of this paper is the focus on the "between order and chaos" paradigm (see below), along the lines outlined by the author in [31], Chapter 6 .

A central concept of complex systems theory is "self-organization". The meaning given in this context should not be confused with the use of the same expression in reference to grassroots-based social structures without hierarchy. In complex systems theory, self-organization consists of the generation of complexity without following prior designs or templates, whether or not the resulting complex structures involve some kind of hierarchy. A closely related concept is "emergent property". This expression is used when a large set of interacting elements self-organizes, giving rise to a system whose properties could not be trivially deduced from the nature of the elements and their rules of interaction. For example, recessions have been a recurrent feature of capitalism, but there is no trivial way to explain their existence and features based on microeconomics; hence, recessions are an emergent property of capitalism. A key limitation of most utopian thinking to date is that, when considering the interaction among different agents, it has sought to design rules that are fair in themselves, i.e., on a small scale, expecting that they will also lead to a fair society on a larger scale, without studying the emergent properties that might arise out of these rules. Such a study was hardly feasible without recent developments in complex systems theory.

The field of study of ecological econophysics as here defined is vast, and it could be approached in many different ways. In particular, this paper takes as its starting point a hypothesis that has received much attention from complexity scientists [24]: that long-lasting complex systems are necessarily poised at some point "between order and chaos" (BOC) (in this paper, I use the acronym "BOC" as an adverb, replacing the adverbial phrase "between order and chaos", except where I refer to BOC as a paradigm). This idea is given a more precise meaning and developed throughout the paper. It is seen by the author as crucial to understand the current economic system and to identify which other imaginable systems would be viable in practice. Degrowth will probably imply major structural changes, so it is essential to understand the limits to the malleability of the economic system's architecture. The need for a long-lived economic system to stay BOC is probably one basic constraint. Hock's "chaordism" [42] is based on the same scientific paradigm, but I treat it differently; this will be discussed in Section 5.

This paper does not give a finished theory. It is a snapshot of a work in progress with a long way to go. Being addressed to an interdisciplinary audience (but, especially, to scholars working in ecological economics and related disciplines), it contains abundant introductory material on complex systems. Equations have been reduced to a minimum. One of my hopes is to enlist other researchers in the attempt to put econophysics and its sister disciplines at the service of the common good from a degrowth perspective.

Section 2 introduces the BOC paradigm, and Section 3 analyzes its applicability to economics. This section presents mostly (but not exclusively) known results, albeit synthesized in a novel way and accompanied by new interpretations and hypotheses. Based on this synthesis, the remaining sections head into areas that are mostly unexplored. Section 4 discusses how an economy BOC will respond to the impact of the environmental limits to growth. Section 5 discusses the normative aspects of the BOC paradigm. Section 6 explores the consequences of the BOC paradigm in regard to constraints and 
opportunities for the development of environmentally sustainable and socially fair alternatives to the current system, along the lines of degrowth. Section 7 gives some final remarks.

\section{Complexity "between Order and Chaos" (BOC)}

\subsection{Scale Invariance}

Before introducing the concept of BOC, it will be useful to mention an empirical observation about nature: the widespread occurrence of scale-invariant patterns. In a mountain we can distinguish smaller mountains, and in each of them we also find smaller mountains or hills; rivers have smaller tributaries; for each lake and for each island, there is some given number of smaller lakes or islands; and similar regularities are observed in the shapes of clouds and coastlines, in the branching patterns of trees and bronchial tubes and in many other instances. Shapes like these are the object of study of fractal geometry [43]. Often, the proportion between bigger and smaller elements repeats itself once and again, irrespective of how big the bigger element is. Systems displaying these properties are named "scale invariant". Note that, in a map of a region that we do not know, it is often difficult to tell the scale if it is not indicated.

Because of their scale invariance, the great majority of lakes or islands are very small, while a few are extremely large. The frequency distribution of their sizes $x$ follows a power law [43]:

$$
f(x)=k x^{-\beta}
$$

where $k, \beta$ are constants. This distribution tells us that we will observe a straight line when plotting the number of islands of a given size (or their probability density $f$ ) against size in a logarithmic scale:

$$
\log (f(x))=\log (k)-\beta \log (x)
$$

Of course there are no islands with the size of a molecule or of the whole Earth. Power laws hold between two bounds $x_{\text {min }}$ and $x_{\text {max }}$, which, combined with the exponent $\beta$, define the distribution. The constant $k$ is a function of these three parameters and ensures that the probabilities add up to one between the two bounds (e.g., [44]).

Scale invariance is also found in time, besides space. A distribution close to a power law (Equation (1)) has been observed, for example, in the duration of droughts [45] and in the sizes of many types of catastrophic events, such as earthquakes (Gutenberg-Richter law) [46], landslides [47], storms [45], hurricanes [48] and wildland fires [49].

\subsection{Phase Transitions}

Phase transitions are another essential ingredient for the BOC paradigm. A phase transition is what happens, for example, when a solid becomes fluid or a fluid becomes solid. If the solid is a crystal, it is basically ordered, while a fluid is basically chaotic (even though a liquid is not as chaotic as a gas). Magnets give another example. The polarity of a magnet arises because its constituent particles are also polarized and are arranged in an ordered manner. However, if the temperature increases above a critical threshold, particles abandon their ordered arrangement, and the piece of metal loses 
its magnetization [50,51]. In systems undergoing phase transitions, there is no ambiguity in the meaning of "between order and chaos" (BOC): the system is BOC at the critical threshold.

These two cases exemplify two types of phase transition: the switch between a solid and a liquid state is a "first-order phase transition", while the magnet displays a "second-order phase transition". The precise difference is not needed at this point.

(However, for those interested, it comes here [50,51]. To characterize a phase transition from an ordered state, such as a solid, to a more disordered state, such as a fluid, we first need a quantitative parameter that expresses or is closely associated with the degree of order. In the case of a transition from solid to fluid or from fluid to solid, this "order parameter" is the density. Since this phase transition can be induced by cooling down the system, temperature plays the role of a "control parameter". When a threshold temperature is crossed and the system moves from liquid to solid, it typically displays a discontinuous increase of density. As the relation between the control parameter and the order parameter displays a discontinuity, this is a "first-order phase transition". In the case of the magnet, we are dealing with a piece of metal that has a magnetic field because the polarity of its constituent particles is nonrandom. Here, the order parameter is the degree of magnetization or, more properly, the "density of magnetization". Again, temperature can act as a control parameter. Above a critical temperature $T_{c}$, there is no magnetization. If we cool down the metal, magnetization appears as soon as the temperature crosses this critical value. However, we do not have a jump from zero magnetization to a density of magnetization significantly larger than zero. The more we cool down the system, the larger the density of magnetization, with no discontinuity. In mathematical terms, the relationship between the control parameter and the order parameter is continuous, but $T_{c}$ is still special, because the relationship between these two parameters is not differentiable at this point. In this case, we have a "second-order phase transition").

It is important to mention that systems poised at the critical threshold of a second-order transition display scale invariance. In the case of the magnet, we find regions with different polarities, and the sizes of these regions follow a power law (Equation (1)) [51]. Intuitively, scale-invariance can be seen as a property BOC, because, e.g., a fractal chain of mountains is more ordered than a huge set of rocks spread on the ground, but less ordered than the same set of rocks piled in the form of a giant monolith.

There is much evidence that complex systems, e.g., ecosystems, also display phase transitions [51,52]. This will be exemplified with a simple wildland fire model (similar to [53]), which will be a useful reference throughout the paper. Consider a vegetated landscape divided in pixels, with fire in some of the pixels. Each non-burning pixel $i$ has some flammability $p_{i}$, defined as the probability of burning at time $t+1$ if one of its nearest neighbors is burning at time $t$. In an individual pixel, fire only lasts for one unit of time. Once burnt, $p_{i}=0$. Let us start with $p$ being the same for all pixels, or different but arranged at random (more complex situations will be considered in other sections). This simple system displays a second-order phase transition. Above a critical threshold $p_{c}$ (for the mean $p$, i.e., $\bar{p}>p_{c}$ ), the system is "supercritical" and there is a probability larger than zero that a fire starting at one single pixel sustains itself and propagates indefinitely, reaching the borders of the system, whatever its size. At the subcritical state $\left(\bar{p}<p_{c}\right)$, fires are small, and the probability of an indefinitely self-sustaining fire is zero. At criticality $\left(\bar{p}=p_{c}\right)$, fire sizes are scale-invariant, displaying a power law distribution (Equation (1)). 


\subsection{Information Processing BOC}

It has been suggested that self-organized systems can only develop the capacity of complex information processing (in particular, "universal computation") if they are poised between order and chaos (BOC) [24,54-56]. This statement is not, in itself, very informative, because perfect order and perfect chaos are just idealizations, so virtually everything is between order and chaos, whether or not it is a complex system. However, this notion emerged in the context of phase transition theory, where BOC has a well-defined meaning, as shown in Section 2.2. Rather than "between order and chaos", pioneering authors, such as Packard [54] and Langton [55], used the narrower expression "at the edge of chaos", because there is a well-defined "edge" if you have a phase transition. These authors were not particularly interested in ice or magnets: they worked with a huge family of simulated complex systems that did not pretend to recreate any real-world process in particular, but could bear some similarity with many of them. Langton [55] found evidence of a phase transition separating "ordered" from "chaotic" systems, with some in-between systems qualifying for complex information processing.

The actual presence of a phase transition is not a sine qua non condition to benefit from the insights of the BOC paradigm. In this paper, we will define a system BOC as any system displaying properties that are characteristic of phase transitions, regardless of whether or not the system is actually poised at a critical threshold. The most apparent of these properties is scale invariance, but it does not suffice for a system to qualify as being BOC. For example, the shells of some of the later species of an extinct group of mollusks, known as ammonites, display fractal patterns (Figure 330 in [57], p. 455). Once the shell was formed, the doses of order and disorder in its shape were "frozen". Their fossils are still fractal, but, of course, they cannot compute. We will not consider that a scale-invariant system is BOC if it does not evolve.

There are several features of the critical point of a phase transition (especially, of the second-order type) that are useful for complex information processing:

(1) The combination of "solid" features needed for memory with "fluid" features needed for the modification and transmission of information [55].

(2) Scale-invariance, implying correlations at all scales of space and time, thus giving choice for computations of any duration, with information stored at any length, involving communication at any distance, requiring any level of computation resources and having any level of impact on other computations [55].

(3) The extremely long time needed to reach a steady state, if it is ever reached ("critical slowing-down"). Such never-ending transients can embed algorithms for which it is not possible to predict whether they will ever halt [55]. (Together with Items (1) and (2), Item (3) was put forward by Langton [55] as a condition for universal computation. An extremely long relaxation time is precisely the opposite of the general equilibrium assumption of mainstream economics. Assuming general equilibrium is tantamount to assuming that the market does not have the capacity of universal computation).

(4) Their component of unpredictability. While total unpredictability is incompatible with information processing, some dose is useful for exploration and innovation. When an optimization problem is intractable for deterministic algorithms, it can often be handled using the algorithm known 
as "simulated annealing" [58], which imitates a phase transition and, crucially, makes use of random fluctuations.

Neurobiological [59,60] and cognitive [61] processes seem to display scale invariance. Reference [60] gives much evidence in support of this point, but also mentions the results in [62], which might seem to contradict it. However, these results are based on plots of cumulative probabilities, $P(X>x)$. For a power law of parameters $\beta, x_{\min }$ and $x_{\max }$, this function has the form $P(X>x)=\left(x^{-\beta+1}-x_{\max }^{-\beta+1}\right) /$ $\left(x_{\min }^{-\beta+1}-x_{\max }^{-\beta+1}\right)$, which, for finite $x_{\max }$, does not correspond to a straight line in a log-log plot, as assumed in [62]). There also other pieces of evidence that brains are fine-tuned to the critical point of a phase transition [60,63]. Social science also offers a striking example of computation BOC, even though it is not human social science but ants' social science. Studies with the genus Leptothorax suggest that colonies display a phase transition between ordered and chaotic functioning at a critical density, which appears to be close to the usual density in nature. At this critical point, the colony acquires the capacity for universal computation [64]. Casual observation of ant behavior suggests that random-like, chaotic exploration is essential for the search of food, which, once found, is managed in a rather ordered, cooperative manner.

\subsection{Persistence BOC}

Not only too ordered systems are unable to compute, but, in some cases, they are also unstable, or "brittle", as Costanza and Patten [29] put it. An animal can compute because of its brain, which seems to function BOC, as might also be the case for the immune system. However, as a whole, an animal is extremely ordered. Here, the order takes the form of the distribution of tasks. The parts of an animal body are heavily specialized in different functions, which makes them interdependent. As a result, the effects of a local fluctuation, such as, e.g., a cut in a vein, can propagate throughout the system and cause the animal to die. It is the continuous production of "security copies" that allows organisms to increase their order beyond any critical limit without endangering the evolution of life. Their ordered patterns could not be upscaled to the whole biosphere. Gaia [65] can be a living system, but it does not compare to an individual organism (especially, of the animal kingdom). Its name of goddess can be considered sensible in that it could not exist without a different (less ordered) structure that makes it potentially immortal.

The persistence of Gaia not only needs the multiplicity of individual organisms, but also diversity. Otherwise, environmental fluctuations would affect them all in the same way (there is a rich literature about diversity and stability [66]). The set of the abundances of the species in a community follows a power law distribution or nearly so [67]. Therefore, a few species are very abundant and many species are very rare. Most of the latter play a marginal role in the system: probably, many would have no room if the ecosystem were as orderly optimized as an individual organism. However, they are needed for the long-term persistence of the system, because they are candidates to replace the dominant species when these are hit by adverse environmental changes [68]. It is well known that biological evolution needs injections of chaos in the form of mutations and recombination; it might also need some degree of "survival of the unfit" if life is to be able to adapt quickly to unpredictable changes. A completely ordered structure with organisms perfectly adapted to each other would not last for long. 
The model wildland in Section 2.2 is also "brittle" above the critical threshold, where it can be swept away by one single fire event.

\subsection{What Drives Systems BOC}

If nervous or immune systems function BOC, this is probably because they are biologically programmed to do so. However, such genetic programs are a feature of highly-ordered organisms, which are individually unstable and are themselves the result of an evolutionary process that, probably, could only take place BOC. There also have to be spontaneous processes leading systems BOC. We already know some of them.

Any mechanism favoring a continuous increase in order can lead the system BOC if there is a critical degree of order that cannot be crossed, because the system becomes too brittle when approaching it. This is the essence of the phenomenon known as "self-organized criticality" (SOC) [69-71]. For SOC to take place, this "brittleness" should materialize in the form of destructive events that are quick as compared to the process of increasing order. The notion of SOC also applies to quantities that cannot be identified with "order" but that display similar dynamics. SOC has been suggested [70,71] for the many types of catastrophic events displaying power laws, such as wildland fire (Section 2.1).

Let us introduce some more dynamics to the wildland fire model in Sections 2.2 and 2.3 (modeled in [72], related to those in [73,74]). Let us initiate fires at random, in the form of lightning every now and then, and let vegetation recover slowly after the fire. If, after full recovery, individual pixels stay below the threshold $p_{c}$, the system will remain subcritical and fires will be negligible. However, even if individual pixels can attain $p>p_{c}$, the mean $\bar{p}$ will not: the critical threshold is an emergent barrier. The large fires propagating as $\bar{p}$ approaches $p_{c}$ will keep the system confined below this barrier. This gives the first image of the reason why, even though approximate scale invariance only arises for a small range of the possible values of $\bar{p}$, a system can get trapped in this range: hence, the denomination "self-organized criticality". However, things are more complex, even for this simple model. Once the system has approached $p_{c}$, the set of fractal fires gives rise to a fractal pattern of heterogeneous $p$, with some finite regions above criticality (brittle, like individual organisms within the biosphere) and others below (those recently burnt). The average flammability is now self-regulated well below the critical point. However, the range of $\bar{p}$ BOC, in which approximate scale invariance arises, is no longer restricted to a narrow band below $p_{c}$ : now, it is much broader and includes the value of $\bar{p}$ to which the system is attracted [72]. At this stage, the system is sensitive to external factors, such as weather and climate, and responds in ways that can be considered adaptive [72]. Some terrestrial ecosystems do not display SOC [75], but this could be the mechanism underlying the power law or power law-like fire size distribution in other cases [72].

Chain reactions are also essential in processes other than catastrophic events. Biological reproduction is also a chain reaction. Imagine that reproduction events were completely random and independent and that there was no upper bound to population. Then, the total offspring of an individual (including children of children of children, etc.) would display a second-order phase transition, in which the mean reproduction rate would be the control parameter. The critical point would correspond to the replacement rate. Above criticality, there would be a non-zero probability of an infinite offspring, while, below 
criticality, the probability would be zero. At criticality, the offspring of each individual would follow a power law distribution [76]. Since biological populations are often regulated around the replacement rate, this could be seen as a trivial mechanism for criticality. However, regulation is not compatible with random reproduction events, which are a premise for the phase transition. Therefore, the criticality approach will be useful when there is regulation but it is weak. For example, species sharing their ecological niche with many other species will display a critical dynamics ([31], pp. 252-254); this is similar to the mechanism for scale-invariant spatial patterns known as "robust criticality" [77]). Many ecologists are puzzled by simulations showing that "neutral" sets of ecologically identical species display realistic patterns [78]. The resulting distribution of species abundances is close to a power law with $\beta=1$, which, as mentioned, is realistic [67]. However, this is exactly the same distribution that we would expect in the opposite situation, if each species' abundance fitted a distinct niche resulting from an extremely complex set of ecological interactions [79]. Probably, the reality is in between. This is an instance in which a critical process (neutral dynamics) gives a scale-invariant "template" that can embed information (niches) without altering its shape.

\section{Economies between Order and Chaos}

\subsection{Is the Current Economic System BOC?}

The synthesis of observations and arguments in Section 2 strongly suggest that long-lasting complex systems can only function BOC. This is in itself a reason to expect that capitalism also does. Here, I put forward a set of symptoms that collectively suggest that this is the case. This does not mean that each specific symptom or this specific system should be considered unavoidable or legitimate. Desirability and the possibility of avoidance are treated in Sections 5 and 6, respectively.

A centrally planned system would be suspect of being on the "order" side. Whether or not this is necessarily so will be discussed in Section 3.3, but it is not the case of capitalism. Certainly, major corporations and people in the Forbes list are extremely powerful and can exert some planning on the global functioning of the system, but both sets display scale invariance [80], suggesting a functioning BOC rather than either order or chaos.

The sizes of large firms follow a power law distribution (Equation (1)) with an exponent $\beta \approx 2$, according to analyses of large datasets from several countries [81]. Apparently, the first power law distribution in the literature was described by Pareto in 1897 [82] in the personal income data of several countries. He found exponents $\beta$ between 2 and 3. The so-called "Pareto law" has also been found to hold for more recent data of personal income and wealth in several countries, but it is generally restricted to the upper end of the distribution [83]. In the U.S., it was found to hold only for the richest $3 \%$ of the population. However, this represented $20 \%$ of the total income in 2000 (with large interannual fluctuations) [83] and, indeed, corresponds to the "ruling class" performing the key economic information processing. Whether the breakage of the power law at a lower income is inherent to the market or is a result of non-market social regulation merits more study.

The power law covers a much broader range when considering the whole world instead of single countries. From the data in [20], it is easy to show that, on a global scale, per capita consumption 
follows a power law with $\beta \approx 1.4$ for $60 \%-70 \%$ of the world's population. However, it it difficult to separate the signature of market dynamics from institutional factors and colonial heritage.

(Here, I give the details of this observation. Edward [20] integrated information from most countries to estimate the deciles of the global distribution of individual consumption, in 1993 and 2001, in 2002 U.S. dollars at purchasing power parity rates. Having these deciles is equivalent to having the frequency distribution summarized in 10 bins with irregular size but equal probabilities. I examined Edward's results for 2001 (Table 7 in his paper), and I observed that the deciles from fourth to ninth (corresponding to a cumulative probability from 0.3 to 0.9 , i.e., $60 \%$ of the population) are well fitted by a power law with $\beta \approx 1.4$. These bins cover the range from $\$ 626$ to $\$ 6931$. This distribution could well extend to larger values, but we cannot tell where the power law will bend, because, above $\$ 6931$, the table gives one single aggregate probability. If it ends with a sharp cutoff, the power law will also apply to most of the last decile, thus covering $\approx 70 \%$ of the world's population. Note that, apparently, these consumption data are restricted to market transactions, but other, less visible economic activities are also important [84], especially at the lower end of the distribution).

Scale invariance is also observed, for example, in the size distribution [85] and many other features [37] of cities, in communication networks [86] and in financial networks [87].

These are not "frozen" fractals like the shell of the ammonite in Section 2.3. Dynamism and sources of uncertainty are ubiquitous in the economic system. Bauman [88] describes in much detail the ways in which and intensity with which collective dynamism and unpredictability are felt at the level of individual lives. Furthermore, scale invariance has also been found in economic fluctuations. Mandelbrot [89] first observed this property in the changes in the price of cotton. In this case, it is difficult to disentangle the effects of weather from the endogenous dynamics, but this effect has also been observed in other types of financial fluctuations (e.g., [80,90]). Recently, the author also found a power law in the size distribution of GDP contractions [44] (However, this observation results from putting together a broad sample of time series that did not include only capitalist economies), as previously suggested in [91].

\subsection{What Drives the Economic System BOC?}

\subsubsection{Random Growth}

Many of the attempts to explain scale invariance in firm sizes are based on constrained random growth models, similar to the "neutral" ecological model in Section 2.5. However, in that model, the fluctuations in a species are dampened by averaging out the fluctuations in each of its individuals, which gives more stability to more abundant species. In contrast, some studies suggest that the variability in the rate of change of firm size is size-independent (Gibrat's law) [81,92], which would make us think that firms do not benefit from averaging effects. Therefore, firms would generally sustain high degrees of internal order (specialization or uniformity), in spite of the risk of putting all eggs in the same basket. Different baskets do exist, but in the form of separate firms, and according to these results, it would be investors rather than firms who would benefit, by diversifying their portfolios. While the neutral ecological model gives a power law abundance distribution (Equation (1)) with $\beta=1$, from Gibrat's law we would expect $\beta=2$, which corresponds closely [81] to the empirical observations. Other studies suggest 
a slight decrease of volatility in larger firms [93], using, however, data whose representativity has been questioned [80].

A problem with simple random growth models is that they assume that the series of growth rates of a firm through time is uncorrelated. This is not realistic [94], which is not surprising, because most firms have material and intangible assets with long durations. A likely outcome is a correlated random walk, but the correlations do not have to impinge much on the observed size distribution, provided that we still have a random walk. Arguably, a more important point is that it is not clear that, when the set of firms is disaggregated into different sectors, the individual distributions are as broad as the global distribution [95]. This would suggest that what ecologists call a "niche" structure also plays an important role.

Indeed, as in ecosystems, firms" random walks must be only partially "random" and set the basis for a kind of "natural selection", as recognized by evolutionary economics (see Safarzyńska et al. [96] about the application of evolutionary economics to sustainability issues, and, related to this, [97], which is one of the few sources in ecological economics that takes into account models related to the BOC paradigm). In the economic case, there is also a strong "Lamarckian" component, which is the intentional innovation to increase performance, but the last word is still for "natural selection" (or whichever expression we wish to use in this nonnatural but also unplanned context). The action of "natural selection" corresponds to what Schumpeter [98] called "creative destruction". However, firms do not compare to species or genotypes: they are in between species or genotypes and individual organisms. They are like species or genotypes in that they can contract and grow without well-defined bounds and in that they evolve, but are like individuals in their internal coherence. Sets of firms performing a similar activity can be said to occupy the same "niche" ("niche" as this term is traditionally used in ecology, not in the sense that it is given in recent transition studies [96]). The subsets that, in addition, perform these activities in a similar way, compare to species. If firms were individually regulated around a relatively fix niche size, we would have a monopolistic economy (the results in [79] would suggest $\beta \approx 1$ rather than $\beta \approx 2$ in this case). The fact of following a power law distribution still implies that a small proportion of firms will account for most of the market share, but these are likely to correspond to oligopolies more often than monopolies. A monopolistic system would be more ordered and probably brittler.

Similarly to the case of firms, most models of the power law distribution for personal income and wealth are based on random growth processes [99-101]. However, a role for someway predefined economic roles, especially within firms, is likely.

\subsubsection{Self-Organized Criticality}

Self-organized criticality (SOC) has been described in Section 2.5. This BOC mechanism has been put forward as an explanation for scale-invariance where catastrophic events are involved, such as earthquakes and wildland fires [70,71]. Some simple economic models displaying SOC have also been developed [102-106]. It is an interesting candidate as a basis for a theory of recessions. Ormerod and Mounfield [91] suggested that economic contractions follow a power law, and this has been confirmed in a recent analysis by the author [44]. 
In principle, the ingredients for SOC to develop are these (see, e.g., [71]):

(1) The system should be made up of units that can suffer some kind of sudden breakdown.

(2) There should be chain reactions of such breakdown events, following relatively predefined paths.

(3) While unaffected by any such chain reaction, the individual units should have a tendency to increase their vulnerability, crossing at some point from below to above a given critical level.

(4) The time that it takes for a newborn or recovered unit to cross the critical level should be, on average, much longer than the duration of a chain reaction.

Let us examine each of these assumptions in turn (I did this more briefly in the Discussion in [44]). We will assume that the relevant units are firms.

(1) The empirical distributions of growth rates of firms, which are the basis of the models in Section 3.2.1., are quite symmetric in time. However, these analyses do not include firm failure or bankruptcy. This can be seen as a sudden breakdown. Bankruptcies have been found to affect firms of all sizes [107]. SOC dynamics based, for example, on chains of failures, would be compatible with the random growth dynamics in Section 3.2.1.

(2) There are several ways in which fluctuations can propagate in an economy:

- The failure of a single firm can be in itself an instance of a chain reaction. Just like the malfunction of a single organ can cause the death of an animal, the failure of a firm can begin as a small fluctuation in one of its departments or branches or at the management board.

- Sets of firms can be interdependent. There is some dependence when a firm regularly buys a large fraction of the production of another firm or regularly provides a large fraction of the supplies needed by another firm (or it can be indirect, e.g., when many of the customers of a business work in a local firm). The supplier-customer dependence becomes stronger when it involves trade credit. Marx [108] interpreted recessions as chains of failures of interlinked companies and emphasized the role of trade credit. Recently, there has been a renewed interest in chains of failures caused by trade credit, and these have been simulated with agent-based models [109,110]. A study [111] observed a higher-than-random coincidence of bankruptcy in firms with a strong customer-supplier link.

- In addition to trade credit, all other types of credit links can result in the propagation of fluctuations. The case of bank networks is also attracting much interest [112].

- Some products are inputs for the production or complements for the use of other products. When a product is removed from the market, e.g., because of a technological innovation, others follow suit. A recent study [113] found that this effect is quantitatively important. Often, such chains from product to product will also represent chains from firm to firm.

- Rumors propagate and so does mood, largely from person to person [114], and can have a huge economic impact [115].

- Economic tensions can translate to social and political tensions with much economic impact, especially in the case of armed conflicts.

In the second to fourth case, failure in a fragment of the economic system is a direct cause for failure in another similar fragment of the economic system. This is the kind of reaction that 
is contemplated in SOC models. The first case is analogous. It is not so obvious how the last two processes could result in or contribute to SOC (even though SOC has been claimed both for influences among investors [116] and for wars [117]). In case of SOC, the sizes of the chain reactions should follow a power law distribution. In a country, there could be many such reactions taking place simultaneously, but only a few would be large enough to have a discernible impact on GDP, in the form of a recession. Fujiwara et al. [111] plotted the size distribution of the number of firms with strong customer-supplier links that became bankrupt in the same period in Japan, as a proxy for the size distribution of the sizes of bankruptcy chains. The sizes that they observed are mostly small and do not correspond to a power law. (Note added in proof: A more detailed analysis reveals that they are in fact well-fitted by a power law. The reason for the small sizes is not the type of distribution, but the large exponent, $\beta \approx 4$. However, the main implication remains: this distribution is not indicative of SOC. In principle, SOC needs $\beta \leq 2$, because only in this case is the mean of Equation 1 infinite, allowing for indefinitely large sizes at criticality. This evidence, therefore, can indicate absence of SOC or underestimation of avalanche size as stated below. An additional hypothesis is that, similarly to [72], $\beta$ changes in time and that year's macroeconomic context was especially benign). However, the interpretation that should be given to this result is not clear, because: (i) they had to use stringent criteria to avoid "false positives", but this surely produced many "false negatives", since smaller shocks can suffice to cause the bankruptcy of a company if this was already in a fragile situation; and (ii) their study spans one year, but chains of bankruptcies can last longer [118]. There is, though, another reason to question that economic chain reactions can result into SOC: that, besides unit-to-unit transmission, there is also transmission via macroeconomic variables (inflation, interest rates, etc., which are, in fact, the only variables contemplated by mainstream economists). If we are to attribute recessions to SOC, the relative importance of the first type of transmission should be larger, but it is not clear that this is the case.

(3) A trend of increasing vulnerability will result if, in the periods between downturns, concentration tends to increase, either because of large companies outcompeting the smaller ones or because of mergers and acquisitions. As a result, a larger fraction of the economy would become susceptible to fall down simultaneously when a big company fails. This possibility was contemplated in Schumpeter's [98] theory of recessions, but needs more study. Regarding transmission from firm to firm, there are several ways in which firms could become more susceptible in periods of stability:

- Increase in the number of connections (observed in bank networks [112,119]).

- Increase in specialization, similarly to individual organisms in the context of the biosphere according to the view expressed in Section 2.4. Based on Ricardo's view, a classical argument used in favor of free trade is the expected increase in specialization according to comparative advantages. Critics, such as ecological economist Herman Daly [120], have pointed out that this carries with it an increase in vulnerability.

- Increasing leverage, as pointed out by Minsky [121]. Minsky's model of recessions was framed in terms of macroeconomic variables, which gave rise to a periodic cycle. However, it can be re-framed in terms of microscopic interactions. 
- Stretched budgets. For example, because of saturation of the firm's niche in the market (related to the accumulation of capital discussed by Marx [108]) or because of products or means of production that have become obsolete as compared to their competitors' (in this case, crises perform a natural-selection-like role, representing "gales of creative destruction" in the terms of Schumpeter [98]).

These processes are not mutually exclusive. The general notion is that, in periods of stability, firms can diversify into multiple ways of functioning, some of which will not be viable in periods of turmoil. These range from obsolete firms that can survive at the verge of bankruptcy, while their meager sales remain stable, to highly competitive firms that become successful by specializing in a narrow niche of the market and including those that become strongly indebted either by lack of long-term vision or by pursuing ambitious long-term goals needing predictability, plus other idiosyncratic situations that one could imagine. Therefore, the assumption of a trend of increasing vulnerability (after economic turmoil has passed) is plausible, but we have little clue of whether it is strong enough to lead most firms beyond the critical threshold, whichever it is.

(4) The systematic asymmetry between the duration of constructive and destructive processes is perhaps the condition for SOC having the least empirical support. Indeed, constructive processes need time, while destruction can be quick ([31] pp. 102-104), and so it is on some occasions, but destruction can also be slow. GDP time series do not display any clear asymmetry in increases and decreases of GDP (but changes in GDP are a poor indicator of structures being lost or generated). The generation of jobs is generally slower than their destruction [122], but the difference is too small to talk of separation of time scales. Gabaix [123] showed that many macroeconomic fluctuations result from fluctuations in large firms, but these include both increases and decreases in activity, with no apparent asymmetry; moreover, none of the examples that he examined in more detail involved the failure of the firm causing the fluctuation. In regard to avalanches of bankruptcies propagating from firm to firm, the study in [118] showed that they can last several years. SOC is still possible if the birth or recovery of firms is slow enough to prevent a large chain reaction lasting indefinitely thanks to these firms replacing the failed firms, but we do not know if this is the case. That said, sudden destruction certainly exists and plays an important role in economies. Some recessions have a well-defined starting point in the form of a stock market crash. In this case, there is a separation of time scales between an event that instantly causes a subtle but devastating disruption in the organization of the economic fabric, and a recovery that needs years. Time scale separation also seems to hold in the case of wars. However, as mentioned above, it is not clear that these processes correspond to SOC (some exogenous events, such as earthquakes or hurricanes, also cause instantaneous destruction, but these certainly do not result from SOC in economies).

Putting all of the evidence together, economic dynamics are not especially likely to display SOC, but seem to display many similarities to SOC. The mechanism in Section 3.2.1. appears more likely and also gives rise to scale invariance in economic structures, which has a direct translation to macroeconomic fluctuations, as noted in [123]. Intertwined with this process, there is the transmission of economic fluctuations from firm to firm. Probably, firms that have enjoyed a long time of stability become more vulnerable to such economic fluctuations, which can thus result in information processing in the 
vein of "creative destruction" (being clear that this selective mechanism will also remove firms with properties that many economists would consider positive, because they increase efficiency, such as excess specialization). This propagation is probably too slow to give rise to SOC, but it might result in a dynamic that compares to the model in [124], which is also a dynamic BOC, gives a macroscopic outcome with similarities to SOC and was initially interpreted as SOC [124] (this interpretation was refuted in [74]). These gradual constructive and destructive processes are punctuated by events of quick destruction. These are the type of events that we would expect from SOC, but it is not clear that they actually result from SOC. The magnitudes of quick destruction events depend on the size distribution of economic structures, which is scale invariant, probably because of the types of mechanisms mentioned above, which are BOC, but not SOC. One of the joint results of all of these mechanisms, and, probably, others that we ignore, is the scale invariance that is observed in recession sizes [44].

\subsection{Past Economic Systems}

On first inspection, the history of western countries from the Middle Ages to present seems to be one of an increasing fluidification of the economy, moving from the old regime to capitalism and, within capitalism, from modernism to postmodernism, or from "solid modernism" to "liquid modernism" in the terms of Bauman [88]. I have argued that the present system displays symptoms of being BOC and that this might be unavoidable. Then, how come we have previously stayed so long in seemingly more ordered states?

A system BOC can and typically does have parts that are above criticality, such as flammable clusters in the wildland fire model in Section 2.5, individual organisms in the biosphere (Section 2.4) or firms in an economy (Section 3.2.2.). In Medieval Europe, economic agents seem to have lived in a more ordered context, with urban firms organized in guilds and rural workers tied by feudal links. However, these medium-level ordered structures could well be embedded in a system that was BOC at a larger level. Kingdoms and other political structures displayed a strong and largely unpredictable dynamism, with dynastic unions and separations, wars, expansions and collapses. At least in the case of contemporary wars (19th-20th centuries), a power law distribution has been found in the number of casualties [117], which supports the BOC hypothesis. Therefore, western history would not be one of a transition from order to fluidity, but rather the history of a system that has remained BOC all the time, but that included ordered structures that have progressively dissolved and entered the BOC dynamics, being replaced by lower-level ordered structures, such as firms. Some of these lower-level structures have grown larger than the formerly existing medium-level structures. Furthermore, any description of the system as being in a "solid" or a "fluid" state or in between is just partial, because, superimposed on the features belonging to any of these states, there could be an accelerating process of modification of the very nature of the system, whose direction is difficult to anticipate. This contributes to the "liquid" perceptions highlighted by Bauman [88].

A special case is that of real socialism. For most of the 20th century, a major fraction of the world had an economic system that was apparently more ordered than capitalism. There was a strong functional specialization. Of course, many low-level decisions were not made by central planners, but these had much weight. It is tempting to compare the Soviet Union or the whole socialist block to an individual 
organism as described in Section 2.4. An individual animal is not BOC as a whole, but has a huge capacity of computation, because of its brain, which seems to be BOC (Section 2.3). The same holds for the set of brains of Soviet central planners, as for those of any human being. Animals can live for a while, as the USSR did. However, animals are brittle and are damned to suffer a fluctuation spanning the whole system, sooner or later. This is reminiscent of the collapse of the Soviet Union (Bak [70] mentioned it as an instance of supercritical fluctuation, without more details). However, we cannot be sure that this comparison is appropriate, because we still do not have the quantitative tools to tell if an economic structure is really supercritical, and one single collapse is a poor statistical sample, let alone if it takes place under the pressure of a powerful enemy.

Besides the possible threat of collapse, the high order of the USSR's central planning system seems to have carried another problem. The first planners had some definite purposes that were backed by a large fraction of the population: they arrived there in the first place because of a revolution, which is largely a bottom-up mechanism of decision. However, once top-down planning was established, there was no mechanism to avoid planners drifting away from their original purposes. What was expected to maintain the ultimate goals of socialism was not redundancy and active information processing from the bottom up, but only information storage or "memory" in the central planning organs. All memories fade the sooner or the later. Many interpret that Soviet planners soon drifted away from their stated goals. The possibility of alternatives to capitalism and feudalism free from these two problems will be discussed in Section 6.

\section{Interactions with the Environment and Limits to Growth}

\subsection{Relevance of Environmental Constraints}

Section 3.2 discussed possible endogenous bases for economic functioning and fluctuations, but environmental factors also play a role. This is well known in the case of pre-industrial economies. There has been some discussion whether the recessions of early industrialization were also driven by atmospheric fluctuations, via agricultural prices [125]. Keynes [115] thought that, to a large extent, they were. Marx [108] considered this triggering factor, among others. In principle, contemporary industrial and financial crises cannot be attributed to weather or climate, but these factors still have much economic impact at the lower end of the world income distribution. The food price spikes of 2008 and 2010 were triggered by extreme droughts [126], in combination with other factors, and increased the number of undernourished people by hundreds of millions [127]. The increased frequency of extreme atmospheric events like these can be attributed to anthropogenic climate change $[128,129]$. In high income countries, the economic impacts of climate change and other forms of environmental degradation are largely offset in ways that are intensive in energy use (in this text, "energy" is given the conventional meaning given to the word in economics, which is expressed more rigorously with the term "exergy" [130]), but their current sources of energy are vulnerable and unsustainable [131]. Oil supply disruptions have been a significant cause of recessions [132]. Even the IMF, which has been systematically ignoring natural resources and the environment, is now recognizing that peak oil could pose a major threat to economic growth [133]. If future energy shortages reach high income countries, 
these will also become more vulnerable to all other environmental pressures (such as climate change, regional water scarcity, ecosystem degradation, soil erosion and pollution, in addition to the increasing energy cost of obtaining minerals as these become scarce).

When considering at all the problem of dwindling resources and environmental degradation, mainstream economists have generally taken for granted that economic growth will continue unabated, thanks to technological innovation. Growth models include a generic "rate of technological progress" that would be able to sustain growth indefinitely [22]. In contrast to ecological economics [1], mainstream economics does not concede much importance to any of the specific challenges that this technological progress is expected to address. In Section 2.3, I refer generically to the capacities of innovation and adaptation presented by systems BOC, but it would be erroneous to use econophysical arguments to support standard growth models.

Econophysics is an extension of statistical physics, which is based on the fact that, because of statistical effects, the details of a system may be irrelevant if there are many degrees of freedom involved. For example, for most applications, a few state variables, like temperature and pressure, exempt us from the impossible task of quantifying the positions and velocities of each of the molecules in a gas. The parameters of, say, the income distribution (Section 3.2.1.) compare to these state variables and are useful when there are many agents involved. Crucially, the number of degrees of freedom has to be large, above some amount known as the "thermodynamic limit" [134]. Below this limit, averages cannot replace the consideration of specific elements when predicting the dynamics of the system. In the case of energy supply, the possible sources are just a handful. Finding even one single unsuspected source of energy is very unlikely. The increase in the efficiency of technologies, including energy capture, has been found to follow predictable rules [135], which probably result from the fact that the set of all small improvements in a given technology throughout its history does constitute a large number. However, not only discoveries of new energy sources, but also major breakthroughs in the ways to take advantage of known sources are probably rare enough to lie below the thermodynamic limit. Therefore, in this case, expert assessment based on the knowledge of energy physics, engineering and geology should be much more informative than any general rule of innovation. Ironically, mainstream economics combines extreme technological optimism as an argument for the irrelevance of a sustainable use of resources with the advice of balanced government budgets when measured in terms of money, even though the possible sources of income for a single country are effectively open-ended, while this is not the case of the possible sources of, for example, energy for humanity.

In general, a positive relationship between GDP and energy consumption has been found [136]. Even if it is to become ever possible to decouple GDP from natural resource use, with the first increasing and the second declining, this will not necessarily avoid a decline in welfare. Many basic needs have a material nature. Insofar as there is a power law-like income distribution (let alone if compounded with other inequalities, such as those associated with gender within households), basic needs will have to compete for the increasingly limited resources with luxury demands that contribute much less to wellbeing. This trade-off is already apparent in the conflict between biofuel and food [137]. 


\subsection{BOC Systems beyond the Limits to Growth}

Knowing whether the throughput of an economy has reached an unsustainable level is not enough to know how the system will react. For example, the peak oil literature offers, intertwined, several different images of the future oil history. The typical illustration of peak oil portrays a stylized curve of oil extraction that gradually climbs, reaches a maximum and then declines smoothly, the increase and the decrease being symmetric [138]. A similar image would be obtained from a general equilibrium model with limits to growth, as will be shown in a forthcoming paper. However, this image is often accompanied by discussions on the possibility of collapse at some point of the curve, in the tradition of Meadows et al.'s Limits to Growth [139]. Some authors also think that the current economic recession could be a symptom of peak oil [140], and other recessions with the same cause could come in the future. This leaves us at least with three possible scenarios: smooth decline, collapse and succession of crises.

Let us use the wildland fire model in Section 2.5 to explore the plausibility of these patterns of response in a BOC context. In this model, the flammability of each pixel is a function of the amount of fuel. However, in the real world, weather and climate also affect flammability. Reference [72] introduced these factors in a simple way. The flammability $p_{i}$ of pixel $i$ was considered to be the sum of an internal component (fuel, resulting from the system's dynamics, as described in Section 2.5) and an environmental component. The environmental component was assumed equal for all pixels. It could fluctuate either more quickly than fuel accrues, simulating weather, or more slowly, simulating long-term climate.

In Section 2.5, we considered two cases: either the flammability of individual pixels never reaches the critical threshold and the whole system remains subcritical, or they do and the system develops self-organized criticality (SOC), which is a state BOC. When adding weather, the response is different in each case [72]. In the first, there is almost no response unless the system approaches the critical threshold. If the threshold is crossed, the system becomes supercritical, and there is the risk of a giant fire spanning the whole system, which corresponds to a collapse scenario. In the state BOC, the response is more gradual. In this case, as mentioned in Section 2.5, the system displays fire events of all sizes, following a power law distribution (Equation (1)). If the weather becomes more fire-prone, the mean fire size increases, but it still follows a power law: the exponent $\beta$ decreases, thus increasing the proportion of larger fires, and the maximum fire size, $x_{\text {max }}$, increases. A large and quick change carrying our model system beyond criticality would still produce collapse, but if the environmental change is gradual, the increased fire activity removes and rearranges fuel, thus keeping the system below the critical threshold [72]. This is a way in which the system processes information and prevents collapse.

The predicted pattern of response of the power law parameters to weather has been clearly observed in the empirical data of boreal forest fires [72]. It has been observed that tropical cyclones also display a power law distribution and that increases in sea surface temperature cause the upper bound, $x_{\max }$, to increase, while a possible response of $\beta$ was not clear in this case [48]. These results are interesting for future economies in two ways. First, when referring to their own contexts in which they were obtained, they give us a more precise portray of what is meant by increasing the frequency of extreme events caused by climate change. More important in our context, they give clues of the own response of the economic system to environmental pressures. 
According to Section 3.2.2., it is far from evident that the economic system is an instance of SOC. However, in the wildland fire model, the power law fire size distribution and its response to environmental pressures is a reflection of the scale-invariant spatial arrangement of fuel, whether or not this has originated because of SOC. Whatever the reason, the economic system does display scale invariance (Section 3). Its scale-invariant granularity has a strong incidence on macroeconomic fluctuations, as shown in [123]. Its modularity (i.e., the tendency for interacting "grains" to be grouped in clusters) also seems to play a major role [112]. Therefore, it is plausible that economies respond to environmental pressures by increasing the intensity of recessions in a way similar to the model. If this is the case, there will be recessions of many different sizes with or without environmental pressure, but an increasing pressure will translate to an increasing proportion of large recessions and an increasing size of the largest possible recession. This scenario of economic decline reminds a mathematical figure known as the "Devil's staircase": a staircase with steps of all sizes, displaying scale invariance [43] (in the economy, however, we do not only expect clear-cut "steps" down, but a mixture of these with descending "ramps" and partial recoveries).

There is indirect evidence of this type of response in precapitalist societies. When studying several centuries of European history, a statistical association was found between climate adverse to agriculture and increasing fatalities due to wars, in addition to famine and epidemics [141]. A power law distribution of the number of casualties has been observed in contemporary wars [117]. The simplest hypothesis combining both observations is that war size follows a power law whose parameters change as a function of environmental pressure, similarly to forest fires (it should be clear that this does not deny the added impact of purely social factors on these parameters or even the possible existence of societies whose repertoire of responses does not include warfare; such societies simply do not contribute to the data on war casualties analyzed in $[117,141])$.

Looking into the future, the transmission of the impact of oil scarcity from one economic sector to another has been recently modeled by Kerschner et al. [142], and there is some econometric information available on the consequences of past oil shortages for different sectors [143]. A more detailed impact map, e.g., considering individual firms, is not feasible, but its statistical properties can be investigated and, probably, will be as described above.

It is noteworthy that the 2008 financial and economic crisis broke out when the oil price was hitting a historical maximum. There has been some discussion about a possible causal link [12,140,144], but this possibility is not considered by most economists, who focus their attention on other factors. There can be little doubt of the key role of factors such as the real estate bubble, subprime mortgages, the fragile network of asset-backed securities, the huge leverage of the shadow banking system and the inability of countries to perform monetary policies within the Euro area [145]. However, what happens in models BOC, such as the wildland fire model, is that, under environmental pressure, the first parts of the system to fall are those that were already fragile. Because of environmental pressure, these parts become more likely to fall and carry with them a larger fraction of the system. Whether or not oil supply limitations actually played this role in 2008 can only be found out from more research. Meanwhile, we cannot tell for sure whether the current crisis is already one step down in the Devil's staircase beyond the limits to growth. 
There is another phenomenon, unrelated to the processes operating in the SOC fire model, that also contributes to enhanced economic fluctuations under resource scarcity. Peak oil theory assumes that, as scarcity increases, oil supply relies increasingly on resources whose extraction is costly for geological reasons [138,146,147]. It can be added that it also relies increasingly on areas that are unreliable geopolitically (from the point of view of consumer countries and transnational corporations). The oil crises of the 1970s and the 1980s took place after the U.S. had passed through peak oil and the west had become dependent on OPEC countries. In 2011, the IEA [148] estimated that, just to replace depleting fields and keep current oil consumption levels up to 2035, an additional capacity equivalent to twice the current OPEC Middle East rate of extraction would be needed (and more capacity if consumption is to grow). This agency hoped that this oil would be extracted from a set of sources that are uncertain for several reasons, with the largest share attributed to a country that has been suffering as much instability as Iraq. (Here, the IEA uses the term "oil" aggregating crude oil, unconventional oil, condensates and natural gas liquids, such as butane [148]. Regarding conventional crude oil, this institution recognized in 2010 that its rate of extraction probably peaked in 2006 [149]. The projections in the 2013 report differ from previous reports in that it gives much weight to the U.S.'s shale oil, but other sources disagree strongly about the prospects for this resource [150], which means that the uncertainty in energy supply remains).

The approach outlined in this paper differs in several ways from other approaches to the behavior of the economic system beyond the limits to growth. Like Meadows et al. [139] and other models inspired in this pioneering work [151], we overcome the instantaneous relaxation times and the absolute predictability of general equilibrium models, hence allowing for nonlinear behaviors, such as recessions and collapse. However, Meadows et al.'s shared with general equilibrium models their focus on macroeconomic variables (both are "mean field" approaches, in physical terms). Therefore, they did not include granularity and modularity, which set the basis for the notion of a sequence of recessions. Without these features, they had one single large "grain" that had to fall at once, in the form of collapse.

However, the developments in this work do not allow us to discard the possibility of general collapse, for two reasons. First, that "mean field" variables can have importance in themselves (not just as a result of the aggregate of microscopic transmission events). Second, even agent-to-agent transmission can lead to collapse if, for some reason, the system crosses the barrier of criticality, thus becoming supercritical. There are at least two ways in which the last scenario could take place. One is an abrupt environmental change, causing the system to cross at once the distance that separates its current state from the critical point, with no time for any negative feedback to act and carry the system away from this point before crossing it. Since this negative feedback is exercised by the economic crises themselves or whatever catastrophic event, there is also a second possibility: that nothing has triggered some given type of catastrophic event during the time in which the system was becoming increasingly vulnerable. The author warned in 2003 that, due to the quick process of globalization, "there is a fast generation of long-range connections of all kinds, and we cannot rule out that these make the system become "supercritical'" and added that this and other concerns "made it irresponsible a fast process of globalization not preceded by a serious analysis of the consequences" ([31], p. 351). Now, there is evidence that the stability of the world economy was compromised by the quick increase in international connections among banks up to 2008 [112]. The financial crisis might have caused a collapse of the 
global economy if governments had not intervened. Had the crisis taken place later, it could have resulted in collapse even with governments intervening. Similarly to fires removing fuel, the amount of connections dropped sharply with the crisis [112,119]. Subsequently, however, governments have gone ahead with new agreements to force a quick globalization.

There is the possibility that we are in a supercritical state precisely because of the uncertainty, lack of awareness and incapacity of reaction to the environmental limits to growth. During a real estate bubble, many people are in fact aware that the capacity for the market to absorb houses is not infinite; but the limits are uncertain, and most agents do not consider them in their everyday activity. However, once the chain of defaults and bankruptcies begins to propagate, the change of mood propagates even more quickly and contributes to the drastic downturn. The point in time when an event like this happens is named the Minsky moment [145]. Something similar could happen when environmental constraints begin to impinge visibly and definitively on economic growth. While the direct protagonists of the real estate Minsky moment were restricted to a few economic sectors and a few countries, the "ecological economic Minsky moment" could embrace virtually all sectors of the formal economy and all countries.

In Section 3.3, I hypothesized that the Soviet Union had to collapse sooner or later, because it would have been supercritical. The time series analyses in [152] suggest that this event was triggered by peak oil, which took place in this country a little before the economic collapse. This possibility merits more scrutiny.

In fact, we are supercritical in one aspect that is not strictly economic, but is closely related, and supercriticality could well be underway in others. We are supercritical in that the nuclear arsenal can amplify a local fluctuation and send a wave of destruction to the whole planet. Our hope is that this local fluctuation will not happen. Another process that might lead us to supercriticality is the steeply declining agricultural biodiversity, which introduces the possibility of one single pest or disease decimating a major fraction of the world's agricultural production at once [153]. Similarly, the advanced ways to fight against infectious diseases have eased the development of dense urban conglomerates, industrial farms and quick transport all over the world, which represents an excellent culture medium for any infectious agent able to overcome the current protections [154].

A topical issue of relevance in this context is the convenience or not of geoengineering as a replacement for the phasing out of greenhouse gas emissions. One of the most often discussed geoengineering techniques is the injection of aerosol precursors to the stratosphere, to interfere with incoming radiation and compensate for the warming effect of greenhouse gases. In addition to other problems (due to the fact that the compensation is imperfect, so that some of the impacts of greenhouse gases remain and aerosols add their own impacts), a major issue is that $\mathrm{CO}_{2}$ can stay in the atmosphere for hundreds or thousands of years (there is not one single time scale, because the fraction of $\mathrm{CO}_{2}$ that is removed by terrestrial ecosystems and oceans per unit time is decreasing progressively), while stratospheric aerosols have a mean life of a few years. Therefore, once the intervention has begun, we are forced to continue. If carbon accumulates in the atmosphere without global warming thanks to the aerosols, but at some point, the injection of aerosols stops for any reason, the world will warm abruptly [155]. This is an instance in which a small or medium socioeconomic fluctuation would be amplified and affect the whole system. 
Taking all of this into account, if humanity ever has access to some abundant, virtually inexhaustible source of energy (this is the promise of nuclear fusion, but its fulfillment will have to wait, at least, until late in the 21 st century, and it might turn out to be unfeasible; in the quickest scenario, the first commercial plants will begin to operate by about 2050 [156]), sustainability will not be guaranteed, yet. Not only will we need to find ways to avoid that it be used for destructive purposes, but also for constructive purposes in such a quick and ordered way that they result in supercriticality.

\section{Normative Issues and Political Challenges in an Economy BOC}

Some researchers that can be included in the BOC paradigm idealize the BOC state. A clear example is Per Bak, who first introduced self-organized criticality [69]. Bak [70] states that "the most robust state for an economy could be the decentralized self-organized critical state of capitalistic economics" and that this is "the best state that is dynamically achievable". Walker and Cooper [157] also describe how complex systems theory, and the concept of "resilience" in particular, have been widely used in support of laissez-faire policies. "Resilience" was originally introduced in ecology by Holling [158] (review in [30]), within a view akin to the BOC paradigm. It refers to the capacity of some systems to rebuild themselves after a disturbance, but only in some aggregate characteristics, such as biomass or levels of diversity, without recovering details, such as, e.g., the precise species composition. This has to do with the adaptive capacity conferred by biodiversity and discussed in Section 2.4, which requires a combination of order and chaos. Some authors argue that a free market is needed for economic resilience (see [157]).

A relevant author in this context is Dee Hock, best known for having founded VISA. In [42], he describes in detail how he developed and successfully applied management techniques that go beyond the traditional "command and control" approach. After realizing the connections between his practice and the ideas of complex systems theory about self-organization, he coined the adjective "chaordic" for systems BOC, and founded the Chaordic Alliance, devoted to developing and disseminating these concepts and to assist in the evolution of new chaordic organizations expected to "span such diverse areas as education, government, social services, commerce and the environment". It is claimed that these are organizations that "more equitably distribute power and wealth, and are more compatible with the human spirit and the biosphere" [42].

In relation to the chaordic platform, it is worth reminding that, probably, the current system is already chaordic, yet it poses many problems. As explained in Sections 2 and 3.3, systems BOC often contain highly ordered subsystems, such as firms. The kinds of organizations to which the Chaordic Alliance is primarily addressed belong mostly to this category. The Alliance's advices to help these organizations become themselves chaordic are likely to be socially positive (some of the proposals in Section 6 are similar), but this is largely because these advices mix BOC features with moral points. Being "chaordic" is no guarantee in itself. Furthermore, ways to transform the system on a large scale should also be sought, in spite of the fact that it is already "chaordic".

At least if we assume a moral standpoint that does not discriminate between the welfare of different people, there are not many reasons to idealize the BOC state. Some of the very symptoms that led us, in Section 3.1, to conclude that the current system is probably BOC, are far from pleasant. The nearly 
scale-invariant income distribution means that a handful of people are extremely rich while hundreds of millions live in misery, their prospects being even worse in a world of increasing resource scarcity and environmental degradation (Section 4.1). We also mentioned the dynamism and unpredictability of the globalized market, which increasingly permeates individual life histories and becomes a source of psychological distress and degradation, as described in [88].

On the positive side, it is clear that the material standards of living of the majority of people have raised during the last century (impressively in some countries) and that new spaces of freedom have been created. However, this has been done following a path that appears to be unsustainable. A boom-and-bust cycle could well be worse for the welfare of the majority than no boom at all.

One of the most disturbing features of the current economic system is that it is increasingly running on its own, under nobody's control. As with the old saying "not seeing the forest for the trees", the visibility of some of the human pieces of this system makes it difficult to be aware that it is a self-organizing system with the capacity of large-scale computation and emergent properties. For example, the many scale-invariant patterns described in Section 3.1 were designed by nobody, the stock market behaves collectively in ways that nobody can predict, and we can but try to imagine the emergent properties that will follow in the future. In the process of globalization of the last few decades, states have given up their tools to control the market and are themselves increasingly controlled by the market. Attempts of states to regulate the small fraction of the economy within their borders are increasingly overwhelmed by the capacity of the market to regulate political regulations, with capitals flying abroad and local products having to compete with products elaborated without social or environmental requirements or taxes. As described in Section 3.2.1., market self-organization subjects firms to a kind of natural selection. Natural selection might be more favorable to cooperation than had been once thought, but there is little doubt that it also generates behaviors effectively equivalent to selfishness. It would be naive to expect this kind of natural selection to serve the common good as conceived by we humans. Furthermore, if the current patterns of progress of information technology [159] are maintained for some more time, computers will very soon outperform humans even in complex tasks such as firm management, and, therefore, outcompete them in a "natural selection" setting. Using some term or other, the doubts of whether humanity will be able to control the evolution of computers for its own benefit have been put forward by several authors, including the father of cybernetics, Norbert Wiener [160], and the pioneers of "artificial life" [161,162]. However, the role that the type of economic and political system plays in reference to this threat has not usually been taken into account.

In addition, the similarities between economies and ecosystems are no guarantee of sustainable resource use (let alone of avoiding environmental externalities). Overshoots are sometimes found in initial stages of ecosystem development [163]. Even short time horizons could be in part an emergent property of market dynamics and not only a result of human greed and ignorance. For an individual firm, the long-term benefits of being the first occupying one niche in the market (or part of it) may outweigh long-term costs, such as unsustainable resource use. This possible effect, which would belong to the category of "increasing returns" [164], cannot be reproduced by general equilibrium models. 


\section{Are There Alternatives?}

\subsection{Complexity Science and the Quest for Alternatives}

Throughout history, most proposals of alternative systems have relied on little more than moral precepts. Marx did consider system's dynamics, but in an old version that not only downplayed environmental constraints, but also seems to be biased toward the benefits of order. This was understandable in times in which the successes of engineering were apparent and complex systems theory was yet to be born. The irruption of the green movement was a major step forward in that it introduced realism in the form of environmental constraints. These lie at the foundation of some of the earliest green economic platforms [8] and of more recent "degrowth" proposals $[9,10,12]$. One pending step is introducing realism also in inner constraints and potentials, by taking full advantage of complex systems theory. Complex systems theory is still not completely up to the task (which can be bad or good, because this science can also be used for tasks that run in the opposite direction), but it is time to use what we already know or guess in order to outline possible better futures. "Better future" is not an objective category and only makes sense after specifying a moral frame of reference. However, a precise definition of this frame is not needed for the purposes of this paper. For the purposes of this paper, the assumed moral guiding principle is, broadly speaking, the wellbeing of all humans without distinction (the wellbeing of nonhuman organisms is seen by the author as an important issue, but its consideration does not appear to contradict any of the following proposals).

This paper puts together much evidence suggesting that long-lasting complex systems operate between order and chaos (BOC) and that the current economic system is an instance. The evidence for these two propositions is not definitive, but let us assume that they are correct. Does this mean that there is no way to escape the problems inherent to the current system? Not necessarily so, if we are able to conceive more human-friendly (or life-friendly) systems that would also function BOC.

If we accept that the directions that the economic system is taking are detrimental or, at least, considerably dangerous (Section 5), what we can do is try to "tame" its self-organization. I will consider three main aspects: (1) who or what is to tame the economy; (2) how it is to be tamed, with emphasis on distributive issues; and (3) how to address the extra difficulties that arise after the system has overshot environmental sustainability thresholds.

\subsection{Governance}

In a world BOC, solutions might emerge from unsuspected corners and be broadly applied in unplanned manners. For example, it was difficult to predict the prominence that a new form of commons and gift economy would acquire in the context of the Internet, i.e., free software and other free resources. However, we know of nothing intrinsic to self-organization processes guaranteeing anything that we might see as "progress". Section 5 warned that, currently, the global economy is self-organizing in an increasingly autonomous way and in directions that do not appear to be pleasant in terms of the common good. Rather than an optimistic view that things will get fixed "by themselves" or a pessimistic view that we are doomed whatever we do, here, I try to outline what concerned people can do to increase the odds of an optimistic outlook, based only on our current, partial knowledge. One key ingredient is planting 
the right "seeds", by developing alternatives, implementing them on a small scale and communicating them. However, I assume that, in principle, this goal also entails some degree of planning on a larger scale and mechanisms to adjust such plans to the collective i.e., some form of democracy. All of what follows might become obsolete because of some "happy surprise", but is expected to be helpful while this surprise does not show up.

As noted in Section 5, since the economy is currently functioning at a larger scale than any democratic or semi-democratic institution, it is the economy that is increasingly controlling these institutions, rather than the other way round. Many authors and social movements stress the need to reverse this power relation. In principle, this would be accomplished by building a truly democratic global institution with effective power to regulate the economy. While this is not attained, one thing that countries or groups of countries can do is trying to progressively detach from globalization (of course, being ready to face strong pressures and all sorts of problems in the short term). Essentially, this means re-regulating the international mobility of capital, goods and services in a democratic manner.

At the current stage, we can consider many possible forms for this global democratic institution, from a system of bottom-up agreements spanning all scales to a classical parliamentary organ. There is no reason why a hegemony of democracy should be incompatible with the BOC paradigm. There are reasons to suspect that democracy is itself an instance of functioning BOC. It has the positively chaotic component of many people introducing their own points of view, with unavoidable and welcome divergences. It has the ordered component of some of these points of view spreading to attain macroscopic scales, whether or not they are materialized in forms such as political parties. Furthermore, there is evidence of a power law in the distribution of votes per candidate [165]. A condition for the system to be truly BOC and truly democratic is that there should be no mechanism irreversibly locking some points of view or individuals in a state of hegemony.

Some form of delegation of power seems unavoidable if only because a completely direct democracy at this scale would more than oversaturate the physical information processing capabilities of individuals (see also a related issue in [166]), but this does not exclude complementary means of direct participation. For example, some mechanisms are being discussed that would allow one to easily choose each one's level of involvement in decision-making [167].

Whatever the mechanisms chosen, it is vital to avoid that the democratic system falls under the power of the market. This includes the issue of the relative scale of market and democracy already mentioned, but also other aspects, especially the control of mass media, because much of the public political debate takes place in the media. However difficult it might be, democracy needs the separation of media power from economic power (while there is some form of concentrated economic power). Formulas are to be developed to this end (e.g., limiting the economic share of single individuals or firms in media enterprises, in addition to eliminating commercial advertising, which is also problematic for other reasons, and funding media in different ways). Otherwise, there would be little hope for the political preferences of people to evolve as a function of how policies really affect their wellbeing, because collective information processing would be biased by private interests, as it is currently.

For democracy to be resilient, it should probably give ample margin for grassroots movements to develop. These are germs of political organization that function outside the formal institutions. Because of their inherent unpredictability, there is no guarantee for their impact being systematically positive. 
However, they have an irreplaceable role to play in confronting institutions whenever these drift to less "fluid" and less democratic forms of functioning. Order-based ideologies see social movements as a nuisance after their "perfect" social order has been reached, but such movements are clearly needed if we accept that ordered structures are always partial and impermanent in complex systems.

The main message of this section is that, as far as the author can tell, there is no fundamental reason why markets should be predestined to control democratic institutions rather than the other way round.

\subsection{Economic System and Equity}

If we accept that it is possible to build the kind of institution envisaged in Section 6.2, the next question is how it is to "tame" the economic system and in which direction. I have already mentioned the conflict between ethical goals such as equality and BOC features like the nearly scale-invariant income distribution. However, the BOC paradigm does not imply that features like this one should be unavoidable. Assuming that all long-lasting complex systems are BOC does not mean that they should be BOC in all of their dimensions. For example, many terrestrial ecosystems are instances of either self-organized criticality or some other mechanism, leading them to display patterns BOC in their fire regimes, while tropical rainforests are not [75], but are probably BOC in other aspects, such as biodiversity.

Lasting regulation of the economic system on social and ecological grounds can be conceived of by combining two ingredients: (1) a regulating system that is itself BOC, along the lines suggested in Section 6.2; and (2) that the regulation exerted by this institution is not much more than that strictly needed to attain its ultimate goals, leaving ample margin for variability and self-organization whenever there are different paths that lead to these same goals. Once the first item is attained, a strict planning of the economy is imaginable without as much danger of perversion or collapse as the Soviet Union might have suffered (Section 3.3), but removing unneeded rigidities should further reduce such risks by increasing resilience, enhancing distributed computation and exploration, and increasing the overall viability of the project because of an entropy-like effect: the more possibilities you contemplate, the larger the probability of succeeding at least in one of them. This should not be interpreted as a defense of reformism: by limiting regulation to "the strictly needed to attain its ultimate goals", it is meant to really attain the ultimate goal. Furthermore, the free market is just one expression of flexibility. For example, the regulations emitted by the democratic system on a global scale could leave much margin to organize in various ways the local organs of the democratic institution, which could even take varying degrees of control on local economies. Depending on cultural differences, some regions might be more favorable to communal property and others more favorable to private but well-distributed property. More communal economies could be administered from the bottom-up by means of the local organs of the global democratic institution and also by means of other parallel institutions.

Following the BOC philosophy of not putting all eggs in the same basket, all proposals of alternative systems in the literature deserve attention. A most useful research program will consist of scanning such proposals and use a complex systems approach to assess their feasibility and the risk of undesired emergent properties. Complex systems theory teaches us that we should always be ready for unsuspected emergent properties, but also that some emergent properties can be predicted, and gives us tools for doing 
so (proposed models can be studied in a variety of ways, including qualitative assessment, mathematical modeling and analysis, simplified simulations and complex agent-based models). Here, I advance some tentative conclusions, but this is largely a research project for the future.

Midway between theoretical analyses and the application of policies at a large or medium scale, there is an important role for groups of people who, already now, try to practice alternative ways of living at a small scale. These experiences are the experimental arm of the search for alternatives, providing a context in which many innovative solutions emerge, and have a key role in the dissemination of ideas. Complexity scientists can analyze these experiences, provide inputs to try to fix their problems (as already done in [40]) or to explore new possibilities and, crucially, try to anticipate the consequences of attempts at scaling them up.

Just one global alternative model having passed all tests (the different types of analysis and small-scale experiments when applicable) will suffice for us to say that we have a reliable alternative, which is what is missed desperately by many people. The more reliable recipes the better, because this will increase the possibilities that at least one of them is eventually implemented and also of having a convincing "Plan B" if something goes wrong. Furthermore, as the number of recipes increases, there is a combinatorics increase in the number of sets of recipes that could be deployed in parallel in different regions according to differing cultural preferences.

There is a huge literature on mechanisms to increase the environmental sustainability of a market system. Even schools with disparate theoretical foundations, such as ecological economics and environmental economics, agree in the usefulness of some instruments, such as environmental taxes. However, in a context of high inequality, limiting the access to environmental sources and sinks can be an obstacle for a large fraction of the population to fulfill their basic needs (see also Section 4.1). This is a strong reason not to separate environmental sustainability from equity. Furthermore, the treatment of equity is generally perceived as the key point that allows defining different economic systems. Even though there are a number of proposals for alternative systems with enhanced equity, there is a wide perception of a lack of credible alternatives. Two reasons can contribute to this situation: (1) vested interest in sidelining this topic (originating in those favored by the status quo and internalized by others); and (2) its inherent complexity. The theoretical approach presented here will hardly be useful if it does not give answers for this issue. The following paragraphs review and discuss how equity is addressed in several alternative proposals that are not mainly based on command and control and outlines a tentative assessment of the implications of some of these from a complex systems point of view. However, this is mostly research yet to be done.

The "steady-state" model developed by ecological economist Hermann Daly [168,169] provides a convenient starting point, because it seeks the simplest possible changes in the rules of a capitalistic economy that would give rise to a sustainable and equitable system. Daly imagined a market system with privately owned production means, which would be unregulated except for a few clear-cut constraints, to be enforced by public institutions (this is reminiscent of physical systems in thermodynamic equilibrium, which are free to move from one "microstate" to another, but only within a well-defined set of available states, which have to be compatible with some given, often simple, constraints, such as the total available energy). In regard to equity, the constraints would consist of a minimum and a maximum limit to individual income and a maximum limit to individual wealth. People approaching the upper ceiling of 
income or wealth would be heavily taxed, and this would contribute part of the money to warrant the minimum income (another source being payments for access to the limited amount of natural resources that would be made available). Several variations exist on this proposal. Mostly independently of Daly's contributions, there has been much discussion on various forms of minimum income [170,171], ranging from "minimum guaranteed income" to "basic universal income", and complemented to different degrees by the services provided by classical welfare-state institutions. Both the minimum and the maximum income have been embraced by degrowth proponents [172], also contemplating variations, such as a minimum "income" in kind rather than money [173]. Daly's distributive recipe would modify the scale-invariant income and wealth distributions in the conceptually simplest manner: by cutting their extremes away.

In Daly's model, the range of income (and the limit to wealth) could be narrow enough to ensure that nobody has their basic needs unfulfilled and that nobody obtains extra benefits for the sole fact of being already affluent and acquires disproportionate power within the economy. On the other hand, it could be broad enough to ensure that people can benefit from their own work and from their abstinence from consuming and act according to market signals. In this type of market, market signals would truly reflect social preferences within sustainability constraints. In a capitalist market, part of the information processing has to do with a few affluent people having much impact on the market, these people being selected in part by how well their decisions fit market signals, which have however little relation to social preferences and even less to sustainability. The associated nearly power law income distribution is a symptom of the system processing information BOC. By setting ceilings, this process is eliminated, but there can still be self-organization and information processing BOC in other different ways. Patterns of behavior that allow some people getting closer to the upper ceiling to income, or obtaining some given income with less effort, or increasing their life satisfaction for other reasons, would be probably copied by other people. This would suffice to keep in motion the essentials of a natural selection-type mechanism. The resulting distribution of the number of people adhering to each pattern of economic behavior could well be a power law, as it is for species abundances in an ecological community [67], where it can be interpreted as a symptom of information processing BOC (Section 2.3). Medium-scale coherent plans could still emerge from large firms (which could exist in spite of being made up of people with little economic differences among them, for example, but not only, in the form of cooperatives), in addition to the public democratic institutions.

A major problem with Daly's model is the need of severe control and the risk of too strong political pressure from people close to the ceiling to income or wealth, in order to remove or lever it. This is one of the kinds of problems of current alternative proposals in which an econophysical approach can make a difference. Ideally, it would be possible to design economic mechanisms that would lead to some given income distribution as an indirect, emergent result. Besides setting a legal ceiling, we could set rules that make it extremely difficult for a person to reach the ceiling without the need of receiving much direct pressure from the institutions, thus reducing, to some extent, the likelihood of the emergence of a well-defined sector opposing these policies because of their self-interest. Appendix 7 shows how this would be possible based on a simple model of income distribution (following Section 3.2.1.). Probably, this model is not realistic enough, because the mechanisms determining income distribution are not well known. However, the exercise in Appendix 7 gives a prototype for a kind of economic policy modeling 
that merits intensive research (Trigaux [174] also studied, in an econophysical model, how intentional changes in parameters could produce drastic increases in equality). The model in Appendix 7 also contemplates one kind of direct pressure, which is taxing. Besides, it contemplates policies that might indirectly reduce rates of profit, such as the alternative banking formulas mentioned below. An even more promising indirect policy tool is the active assistance to people at the lower end of the income distribution to help them develop their own economic activities. In addition to granting a minimum income, this assistance could be materialized in the form of microcredits, technical and psychosocial support, preference in the supply to public institutions or some kind of certification to attract ethical consumption. If the size of the economy is constrained (by the amount of remaining natural resources or those whose use is allowed or by a saturated demand not stimulated by advertising), increasing income for people at the lower end of the distribution will translate to decreasing income elsewhere. The onus of econophysical models is to predict how this decrease in income will be distributed among the different income classes, considering also the other relevant factors. A nontrivial feature of the simple model in Appendix 7 is that an upper ceiling to income emerges for some parameter values, and the position of this upper ceiling changes as a function of the intensity of active assistance at the lower end of the distribution. The model suggests that changes in banking mechanisms along the lines mentioned below would also bring the ceiling down. It is well known that many complex systems display phase transitions (Section 2.2), i.e., qualitative changes resulting from incremental, quantitative changes in control parameters: in the model in Appendix 7, the consequences of crossing the threshold (where the ceiling emerges) might not be clearly apparent until reaching some given distance away from this critical point, but in other cases, the change can be much more visible (the reason is that Appendix 7's model displays a second-order phase transition, while first-order transitions are more readily apparent; see Section 2.2). This possibility motivates a revision of the dichotomy between "reformism" and "revolutionary change". These are generally distinguished by the methods used to change society. However, this criterion is questionable inasmuch as an incremental change in a tool used for reformist policy can result in an abrupt shift that compares to a revolution. Given the highly technical nature of recipes like these, once better understood they should be recast in a plain language for them to become a subject of popular discussion and not being coopted by powerful minorities wishing to increase inequality rather than decrease it.

While Daly's is a top-down recipe that attempts to force some given global results, most "alternative" economic recipes are based on rules of interaction among agents, whose global consequences, if generalized, are not trivial to predict. Most of these have been grouped under labels such as "solidarity economy", "social economy" and "social and solidarity economy" [175,176] (henceforth, just social economy). There is a long history of implementation of such recipes on a limited scale, coexisting with the hegemonic capitalistic patterns of economic relations $[175,176]$. Therefore, they have been emerging from the bottom up, even though they might also need top-down support if they are to become the norm. These include cooperatives of production, consumption and credit, mutual aid associations, ethical banking (with credits conditional upon environmental and social criteria), and small experiences of alternative markets such as local exchange trading systems (LETS) [177], which are based on collective interest-free credit. There is a potential for synergy among these types of experiences, which have been seen as pieces for a completely different system by several writers, already in the 19th century (e.g., 
Proudhon [178]) and also nowadays [176,179]. For example, credits granted by a public or collectively owned banking system could be interest-free, while avoiding an imbalance between offer and demand by setting social and environmental benefits as a "price". Such credit conditions would give a chance for low-income people (e.g., grouped in cooperatives) to overcome their dependence upon the owners of capital. A "social economic" market would self-organize subject to some basic rules of interaction, and like other markets, it would possibly function BOC. The long experience with social economy all over the world, especially with cooperatives, gives empirical support to its feasibility [176,180,181] and allows identifying barriers to its propagation [182]. An important topic of research is the design of policies that would allow overcoming these barriers (e.g., the credit system described above). One hypothesis is that this is easy enough to be able to reach an overwhelming dominance of cooperatives without a great cost in terms of economic performance and control effort. A different hypothesis is that cooperatives are too difficult to generalize because they imply quite specific patterns of relations, perhaps reducing the available states of the system more than really needed. The later case would lead us to favor proposals such as Felber's [179], who would enforce the cooperative structure legally, but only for firms above some given size (while promoting cooperativism also among smaller firms and setting constraints on the differences of salary in all cases). Another important research topic, needing an econophysical approach, is the global consequences for sustainability and equity if social economic structures become hegemonic. Even though a social economy developing in a democratic context is not entirely comparable to cooperativism under an authoritarian regime, the Yugoslavian experience is a major source of empirical information. This suggests that cooperativism is effective in reducing inequality within firms [183] (which is coherent with their image elsewhere), but not so much in reducing other dimensions of inequality [183], thus needing to be complemented by other policies (several possibilities are mentioned throughout this section).

Felber [179] has recently popularized a specific proposal to put together different social economic initiatives in a coherent system, under the label of economy for the "common good" (this label had also been applied to Daly's steady-state economy [184]). This proposal aims to gradually transform conventional firms into social firms (or gradually replace the first with the last). The main tool that it contemplates is the "common good balance sheet", which would label each firm's social and environmental performance according to a standardized set of democratically-chosen criteria. This balance sheet is expected to have an increasing influence on the decisions of public and private consumption and investment. Therefore, this transformation would not rely on command and control methods (legal constraints are contemplated, as mentioned above, but only after the transformation is largely done), but, rather, on altering the natural selection-like pressures to which firms are exposed. The proposal depicts a gradual, self-organized transition taking advantage of "distributed computation" and allowing for a diversity of paths to emerge, which is coherent with the BOC paradigm. However, the potential for this recipe to deliver the expected transformation is still unknown. Furthermore, the proposal would benefit from a detailed econophysical analysis to refine it and prevent unintended consequences. For example, among the behaviors that Felber suggests to favor, there is cooperation and mutual help among firms: it is important to make sure that this is not implemented in a way that generates clusters of interdependent firms that might be too brittle (see Sections 2.4 and 3.2.2.). 
As is well known, the private property of the means of production is left behind in some of the most radical alternatives. In industrial societies, most real-world instances have taken place under authoritarian regimes, whose problems have already been discussed. However, in Catalonia, there was an experience of generalized, bottom-up, democratically-ruled collectivization $[185,186]$. This was an attempt to move directly to the kind of society that could be imagined as the asymptotic result of recipes like Felber's. The experiment was soon stopped by its opponents. Recently, Ackerman [187] discussed how the increasing separation between ownership and management in contemporary capitalism suggests ways to move to a scenario of public property of the means of production, while conserving some of the dynamic and informational advantages of capitalist markets.

While a guaranteed minimum income or a universal basic income would ensure that some basic needs are covered and cooperativism or analogous patterns of organization would ensure fair relations of production, neither ensures employment. Employment is not only a means to obtain income, but also a potential way for a person to contribute to society (inasmuch as the type of economic activity is socially beneficial, which, however, is often not the case in the current context). This is positive both for society and for the individual's self-esteem and social integration [188]. Even though it is certainly not the only way to contribute to society, solutions are needed to avoid involuntary unemployment. This need is repeatedly put forward as an argument to foster economic growth at any price. However, indefinite economic growth is unlikely to be feasible (Section 4), and maintaining growth in the short term makes long-term sustainability more difficult to achieve in a form that is socially acceptable. An alternative with a long history in the context of the worker movement is the regulation of working time to foster work sharing. This proposal was embraced by the German Greens as a part of their antiproductivist platforms in the 1980s [8] and more recently by degrowth proponents [189]. These proposals should be clearly distinguished from part-time working schemes associated with precarious working conditions. However, to some extent, they are already feasible in a capitalist context and, in different forms, can be applied in any system in which there is a relatively well-defined working time (there are instances of this [185]). Since markets are not generally in equilibrium, the full benefits of reducing working time will take some time to materialize, but this lag can be shortened by active labor policies. However, there are some controversies about work sharing in the literature [189]. Some mainstream economists question the effectiveness of reducing working time as a tool to create net employment, based, however, on inconclusive empirical evidence. Another issue is that, while in a degrowth process many economic activities would be removed, others might demand more work, because of a possible decrease in productivity in a world with less natural resources (discussed in [190,191]). Therefore, it is difficult to know if, in an environmentally sustainable society, there will be more or less work to do. This will largely depend on future developments in fields such as renewable energy, other environmentally-friendly technologies and agroecology. In any case, the need for hard work to secure sustainability does not justify hard work in activities that accelerate resource depletion and environmental degradation, as is the case for most current economic activities. Since we cannot take for granted that the need of labor will change following a unidirectional trend (because of the uncertainty in long-term needs and also because of shorter-term economic cycles), it would be most convenient to have institutional arrangements to share the demanded work, both when it decreases and when it increases [192]. The most trivial mechanism would be a succession of adaptive changes in the standard working week. Another mechanism would 
be taxing long working weeks in order to penalize them and to raise funds to incentivize shorter (but not precarious) working schemes. This would automatize the adaptation of the average working time to evolving needs at a societal level, while easing the adaptation of firms to the changes in average working time. However, any specific recipe focusing on the part of working time that is formalized and quantified should also consider its indirect effects on less visible forms of work. For example, the German Greens in their 1983 social platform ([193], reviewed in [8]) prioritized the reduction of the working week over formulas such as earlier retirement or longer vacations (we can add sabbatical years, which are proposed in [179]), because only the first eases the sharing of unpaid work between genders.

A discussion of economic alternatives would be clearly incomplete if it only contemplated the part of economic activity that is currently monetized, formalized, visible and hegemonic. Feminist economics [194] highlights that the functioning of the current economic system largely relies on other types of work, which is disproportionately carried out by women. In another strand of discourse, some authors have emphasized the virtues of non-monetized activities as an alternative, at least partial, to the currently hegemonic economic relations [84]. Arguably, such activities have an affective added value and also a positive cultural effect in that they can help in preventing simplistic unidimensional thinking focusing on money, which is at odds with the mentality needed to reach sustainability in all of its irreducible [195] dimensions. Some non-monetized activities, and activities that are partially monetized and labeled as informal, have been praised for other purported benefits, including equity [84]. While there are good arguments for the promotion of some non-monetized economic activities, it would be unrealistic to aggregate all of them in a single category and evaluate them accordingly. This is the realm of traditional communal settings and of promising alternatives, but also of injustices ranging from inequality within modern households to feudal relations and soft slavery. Probably the best that can be done with non-monetized economy is to make it visible in order to fight its worst expressions, identify its potentialities and develop the later. Since there is no discontinuity between non-monetized economy and affective relations, some of the most promising alternatives in this area (e.g., [196]) have little relation to economics as usually understood.

In the current context, "non-monetized economy" is closely related (but not equivalent) to "informal economy", which consists of activities that are relatively decoupled from the main control circuitry of the society. From a BOC point of view, the "informal" has an important role: by lying apart from the dominant order, it contributes to the chaos that society needs, being a source of innovation and experimentation. The informal sphere is an obvious niche for small-scale alternative projects. However, when some of these innovations propagate, they can become a new order. As such, they should be filtered according to collective interest. The task of filtering would belong to a truly democratic institution as portrayed in Section 6.2, complemented and in interaction with social movements. One of the aims of this task is to confront emerging patterns of economic relations based, for example, on exploitation, discrimination or environmental degradation. Complex systems theory teaches us that also some initiatives that are well intentioned, and that function well while they are young and anecdotal, could have undesirable consequences as they age and propagate, in the form of unsought emergent properties. For example, one could agree with parents that prefer to educate their children at home to give them some values that they might not encounter at mainstream schools. However, if educating children at home becomes the norm and this includes older children, the frontier between education and work can 
easily get blurred, giving rise to competitive pressure in favor of families taking advantage of children' labor, as has been common throughout history and is currently common in a large part of the planet. In its turn, this creates an incentive for reproduction, which either is compensated for by larger mortality or leads, transiently, to demographic growth. Being demography a key component of sustainability, it cannot be overlooked that volunteer reductions of natality have been associated with the partial transfer of some economic functions from the domestic to the "formal" sphere, including education, social security, retirement and women's work (which, precisely, give keys for a left-wing response to the demographic issue [197]). All of these are factors to be considered when seeking the most desirable partition between the "formal" economy (also, and especially, when it is no longer capitalist) and other realities that can coexist with it.

It is absolutely essential that a change toward sustainability and equality considers the international dimension. While early in the 19th century (when most contemporary ideologies were born), within-country inequality accounted for about $70 \%$ of global inequality, in 2002, it represented only about $20 \%$, the rest being accounted for by differences among countries [198]. Furthermore, some of the main environmental problems have a global nature, and the international economy has a major impact on domestic economic policies. There is a large literature about measures for justice in the global economy, e.g., the abolition of unfair financial debts and the recognition of ecological debts, the elimination of structural adjustment plans as multilateral institutions are democratized, global agreements to control and tax international financial fluxes, the removal of the barriers to the dissemination of technology posed by some intellectual property rules, removal of barriers to migration, and fair and ambitious agreements to manage the global environmental commons (e.g., mitigating climate change). This is a huge area that will not be treated in detail. It is indeed related to the discussion about a global democratic system in Section 6.2. An interesting issue is the kind of international economic treaties that could replace the current ones. In the context of the World Trade Organization (WTO) (and, previously, the General Agreement on Tariffs and Trade, GATT), countries can integrate into the global market at varying speeds; however, at each step, they assume rules to be applied systematically in their relations to every other country, rather than negotiating bilateral agreements. This setting has elements of order and of disorder that could be reproduced in other schemes more useful for our purposes. However, there would be major changes in other aspects. The bias toward integration would be removed, allowing also for progressive separation from the international market whenever this is the choice of a country. Openness to trade with other countries would be systematically conditional upon compatibility in social and environmental standards (which could otherwise be threatened by market dynamics). Simultaneously, there would be a systematic advantage for low income countries. However, rather than preferential access to the markets of high income countries (which can only favor low income countries by means of a trickle-down effect that will vanish as soon as there is no more growth [21] and that is extremely inefficient even with growth [20]), these would be granted a higher capacity to protect their domestic production from international competition. The development of a pattern of economic relations among countries favoring equality would benefit from the same type of modeling approach that is outlined in Appendix 7 for relations among individuals (or households). 


\subsection{Is Degrowth Possible?}

Sections 6.2 and 6.3 discussed the feasibility of a society that is sustainable, equitable and democratic. All of these are features of "degrowth" as defined in the Introduction. However, what gives its name to degrowth is the idea of moving to a society like this once we have already overshot the sustainable levels of throughput. Here, I consider the extra difficulties that this point of departure implies.

By generalizing the ecological notions of "succession" and "disturbance", Margalef ([199], p. 234; see also [200], pp. 88, 90) postulated that the biosphere, at all scales, displays two types of changes: "slow" changes that increase "organization" and "quick" changes that "simplify". The latter include, e.g., the death of an individual organism, a fire in a forest or the extinction of dinosaurs, while the first type of change includes the growth of an organism, the development of a forest in a burned area and the evolution of the many groups of mammals and birds occupying the empty niches left by dinosaurs. In an essay entitled Progress: an enthusiastic subjective appraisal of almost half the changes in living systems [201], Margalef wrote, taking individual organisms as an example: "We are born and we grow, but we do not degrow. Instead, we die" ("Nacemos y crecemos, pero no 'descrecemos'. En vez de eso nos morimos." [201]). In this essay, he did not refer to the political project of degrowth; however, is he telling us that this project is too optimistic given the nature of complex systems? Here, I argue that economic degrowth is certainly difficult and nontrivial, but again, there are no reasons to think that it is impossible. However, the more we wait, the more unlikely it is that we manage to degrow rather than collapse or suffer a sequence of crises.

The first point to consider is that economic growth is not really the economic analogue of ecological succession. While terrestrial ecosystems typically increase biological production (and therefore, energetic and material throughput) until reaching a plateau, planktonic ecosystems often decrease production at later stages of succession (in fact, if we consider long enough time scales, instances of gradually decreasing production are also found in land ecosystems; these have been named "retrogression" [202]). As conceptualized by Margalef [163,203], planktonic succession typically starts when an injection of nutrients spurs the quick growth of plankton, initially in the form of small organisms with short life cycles. During this initial phase with intensive growth, the use of nutrients is unsustainable: many are lost to deeper water layers as bodies and excrement sink (once there, they are not usable, because there is no light for photosynthesis). Afterwards, succession proceeds while production, and often biomass, decrease. The small and simple organisms are partially replaced by others that are larger, reproduce less, have longer life cycles and, in some sense, can be considered more complex. This is the case of dinoflagellates, which, unlike other types of phytoplankton (such as diatoms), can swim actively. Therefore, they can avoid sinking for a longer time and can travel periodically to deeper layers, where they can recycle some of the sinking nutrients. According to Margalef, rather than an increase in biomass, and even less in production, the most general regularity of succession is the decrease in turnover (longer lives) and, related to this, the reduction in the amount of energy used to sustain a given amount of biomass. When trying to be more general and include anthropic systems with its artifacts, Margalef replaces "biomass" by "total mass with the capacity of controlling the future" [163]. Many measures promoted by the degrowth movement would reduce GDP, but should be interpreted as steps forward in some economic analogue of ecosystem maturity better than GDP. This is the case, 
for example, of eliminating programmed obsolescence and non-reusable items and producing, instead, long-lasting items, i.e., reducing turnover. It is also the case of energy-saving measures, such as avoiding unneeded transport. If our economy is to follow a path similar to ecological succession, we can expect the following transformations: (1) a move from the use of nonrenewable energies and raw materials to renewable energies and recycling (think, e.g., of a tropical rainforest: a complex and mature system that lives out of solar energy and recycles most of its nutrients); (2) increased efficiency in the use of resources; (3) increased duration of products and installations; (4) probably, reduction in throughput; (5) possibly, reduction in capital; (6) reduction in the ratio between production and capital (in a broad sense, including "human capital"); (7) increase in "complexity" (at least, a kind of complexity consisting of sophistication that allows for an efficient use of resources and that can take many forms, ranging from advanced computing to permacultural wisdom). These changes would be gradual and, therefore, consistent with the idea of degrowth.

This comparison can give us some confidence in that degrowth is possible, but it does not suffice to take for granted that it will occur. There are at least four reasons not to rest on our laurels:

- The exhaustion of resources might become too severe for a gradual adjustment to be the default response of the economic system. We might be more similar to a locust swarm, growing explosively and then collapsing, than to a planktonic ecosystem responding gradually to a progressive loss of nutrients.

- The role of stocks and fluxes is different in ecological and in economic dynamics. Many ecosystem disturbances cause primarily a loss in the stock of biomass. For example, a storm causing trees to fall. Some of these disturbances propagate, such as fire. Also in economies, some disturbances cause primarily a loss in the stock of people and capital, e.g., a hurricane. There are also instances of societal propagation of fluctuations destroying this stock: wars and epidemics. However, economies appear to be much more susceptible than ecosystems to the propagation of fluctuations affecting fluxes. The reason is that the proportion of interactions with a cooperative nature appears to be much larger in a market economy than in an ecosystem, and these interactions involve fluxes. Even when they are unequal, indirectly forced and exploitative, capitalist interactions essentially consist of cooperation in the generation of economic fluxes. Such interactions involve positive feedbacks, which have a destabilizing nature [204]. As a result, production crises occur (Section 3.2.2.), and it is straightforward to think that they should be magnified under environmental pressure, as discussed in Section 4.2.

- Even if the economy has a succession-type response to scarcity (rather than receiving scarcity as a disturbance), the results could be far from socially optimal. For example, forest succession responds gradually to resource limitation, but in a way that, if translated to society, would be anything but desirable. By the process of self-culling, a small fraction of the trees grow large and occupy most of the area, while the rest die. Similarly, if a capitalist economy happens to respond gradually and adapt to resource limitation, it will probably be with a minority of people concentrating the available resources while the rest are pauperized or dead (or even with autopoietic networks of machines gradually outcompeting humanity).

- Here, we are concentrating on the analogues of succession and disturbance in the economic system, but additionally, economic growth acts as a disturbance for the biosphere. At this level, 
the separation of time scales is clear: several components of the environmental degradation that has occurred in a few generations will entail centuries, millennia or millions of years of recovery. Therefore, if we wait for degrowth to "happen by itself", we will probably live for many generations in a much more degraded world than if we activate it as soon as possible.

The elimination of a complex structure needs many less logical steps than its construction, and therefore, it is often eliminated much quicker than it is built. This is likely to be the ultimate explanation for Margalef's observation ([31] pp. 102-104). However, there are many different ways to eliminate a structure, with different implications. Some ways are simple, but others are complex. We sometimes have the choice to eliminate the structure in some preferred, nontrivial way that does need many logical steps and much time. We can break a machine, but can also take it into pieces, and the removal of an organ can be ordered to a slaughterer, but also to a surgeon. Similarly, there is no fundamental reason why we cannot have degrowth rather than collapse or crises. In fact, we noted in Section 3.2.2. that the separation of time scales is not always evident in economic crises, which is encouraging in relation to the feasibility of degrowth. However, as the above comparisons suggest, degrowth will be intensive in information. The recipes for degrowth are still underdeveloped. Here, I follow some suggestions for the kind of measures that we might need to apply accompanying the removal of environmentally unsustainable activities, if we do not want this removal to trigger uncontrolled fluctuations (measures like these can also be used in case of cyclical downturns, which are likely to take place also in non-capitalist systems, albeit with different intensities and in different forms):

- Build any needed structure and function, while we dismantle those that we do not need. The process will be more similar to "succession" than to a "disturbance" if, in general terms, the construction of sustainable alternatives (e.g., renewable energy installations [205,206] in the context of a sound spatial planning, organic agriculture, clean production and transportation and, also, a new cultural framework) does not lag behind the removal of unsustainable structures and functions (being clear that many of the latter will need no replacement).

- Conserve information that might appear superfluous now, but will regain value in a low-energy context, such as the genetic information in agricultural landraces and the cultural information of traditional knowledge.

- Generate a structure of incentives and disincentives (e.g., taxes) that anticipates future needs.

- Be selective in public rescues of endangered firms. Indiscriminate rescues and generic anticyclical policies risk generating a fragile economic network that ends up falling down synchronously.

- Map the network of economic connections and act carefully, in a "surgical manner", upon firms that occupy a keystone position in this network, to avoid their functioning as amplifiers of undesired fluctuations. Regulate specific types of connections.

- Place a safety net for people who might transiently lose their source of income (e.g., a basic income, Section 6.3). If applicable, implement policies to assist them in moving to new jobs. Complement these with strong public services.

- "Fluidify firms" (without producing inequality; Section 6.3 gives some clues) to smooth the transfer of capital and workforce from unneeded to needed activities. On first inspection, this is reminiscent of the "flexicurity" approach practiced in Denmark and formally embraced by 
the European Union, which reduces security in job tenure in exchange for a strong social safety net, training and help to find new jobs [207]. "Flexicurity" is a portmanteau that, like "chaordic", combines a "chaos"-related concept (flexibility) with an "order"-related concept (security). Unfortunately, according to some authors [207], European flexicurity policies would be a way to disguise increases in flexibility without real increases in security. Furthermore, in the context of these policies, "flexibility" is identified with leaving decisions to the discretion of capital owners and their agents. More coherent with the philosophy of degrowth would be a kind of flexibilization that develops parallel to a democratization of the relations of production. If, for example, society chooses to make a transition from conventional firms to cooperatives, mechanisms should be sought to ease the mobility of workers and capital from one cooperative to another. In fact, according to some studies [182], the lack of mobility would be a key factor explaining that cooperativism is not more prevalent at present. A major obstacle to mobility is that workers generally contribute a part of the capital of the cooperative when they join it, but they no longer benefit from their investment after they leave it. Some solutions have been tried, such as monetary compensations upon the worker separation or tradable membership titles [182], but this field needs much more research. An appropriate form of fluidification would make a difference in the dynamics of economic fluctuations. SOC and similar mechanisms (Section 3.2.2.) occur when there is is friction; this causes tension to accumulate gradually and be released in bursts, which are difficult to manage. In contrast, the models discussed in Section 3.2.1.assume no friction and result in a smooth evolution of the system, which has different implications, even though both are instances of dynamics BOC.

- Regulate working time according to needs, both when these decrease and when these increase (Section 6.3).

- Change the credit system. As discussed in Section 3.2.2., debts are a key factor for the propagation of fluctuations in economic systems. Since moving beyond the limits to growth is not comparable to a transient recession, an intervention on debt cannot be restricted to helping de-leverage firms and citizens and, afterwards, restarting the same game. Furthermore, we are assuming that we want to build a more ethical society. Therefore, the first step is to audit debts on ethical grounds, as currently done by some grassroots organizations, and restructure debt accordingly. Furthermore, rules for interests should be reformulated. Even without economic growth, interests can exist [169], because lenders may want a compensation for delaying their consumption and for the risk of default. Even in an economy that does not grow on aggregate, the economic situation of individual agents and firms will fluctuate, so at some moments they may need credit, and at other moments they may be able to repay the credit plus some interest. The difference will be that, without growth, neither the aggregate flux of loans nor the corresponding flux of interest payments will display an increasing trend. However, it is possible to make political decisions that subvert the mechanism of credit, such as replacing private credit in exchange for monetary interests by collective credit in exchange for societal and environmental benefits (Section 6.3). Furthermore, if interests conserve their monetary nature, they do not necessarily have to follow the pattern of compound interest. As noted by Soddy as early as 1926 [208], debts can grow to infinity, while production cannot. A non-growth system with compound interest could still 
function, but it would imply that some agents are permanently subordinated to other agents by unpayable debts (as is already the case with regard to the external debts of many countries) or a cyclical dissipation of debt in the form of isolated bankruptcies or, more probably, of crises consisting of chains of bankruptcies (well above the minimum needed for creative destruction). Neither of these scenarios is ideal. Furthermore, compound interest is difficult to justify without growth. While the economy grows, compound interest might be explained by an exponentially increasing opportunity cost, but this is not the case without growth. Therefore, if we tolerate monetary interests, it could be with new rules, such that, when it is not possible to repay a credit before the agreed-upon deadline, interests accumulate at decreasing rates and converge to a finite amount, instead of increasing exponentially. Note that the penalties for breaking laws, which have some similarity to debts, expire after some time instead of becoming more serious. Furthermore, note that psychological studies systematically find a nonexponential discount of the future [209], which is not easily reconciled with compound interest.

Recipes like these would probably prevent crises triggered by the reduction of throughput itself. However, another type of crisis will be much more difficult to avoid: the conflicts that will arise because of the attempt to increase equality. However, economic contraction would have unbearable social costs in the absence of a vigorous redistribution.

\section{Final Remarks}

Starting before the current economic crisis and continuing to nowadays, there has been a crisis in the social movements striving for a deep change in the economic system toward sustainability, equality and democracy. Those who prefer "business as usual" know what they want and support their points with sophisticated technical arguments that are widely perceived as being credible, in spite of a faux pas as visible as the failure to foresee or even contemplate the possibility of a crisis like the current one. Opponents have been effective in pinpointing the flaws in the foundations of hegemonic theories and the terrible consequences for societies and the biosphere when these are applied and, also, in thinking of alternatives and applying them on a limited scale. However, these alternatives are mostly partial, and there is a deficit of well-defined plans for a general reorientation of societies with a solid basis. The present paper is a snapshot of a work in progress to contribute to the solid theory that we need. It does not pretend to give all the answers, but at least, to convey the message that these answers can be obtained and to give some suggestions on how to obtain them. The goal of this work in progress is not to replace an economic theory impregnated by right-wing ideology with an economic theory impregnated by green ideology. While ideological biases in the perception of reality cannot be fully avoided, the author gives much importance to the attempt to avoid them as much as possible. Otherwise, I would perhaps not be so interested in complex systems theory, which, also, has largely developed under rightwing influences (as visible in the historical account in [24]; see also Section 5). I conceive of the alternative theory as, first of all, more realistic, because it will recognize a host of realities largely ignored (but less now than in the near past) by the hegemonic view, notably environmental constraints and the nonequilibrium nature of economic dynamics. The ideological compromise has a major role to play, but not one of generating a new delusion to replace the hegemonic delusion. Rather, its role lies in identifying 
the areas that need further study in order to develop a reliable toolkit for social transformation and, most importantly, applying it. The limitations of our current toolkit often lead us to the belief that there is no way to attain the goals that we want to attain. However, it is hardly surprising that we have a deficit of tools to improve equity if economists have been focusing on representative-agent models in which the distributions of income and of wealth are undefined (and nonmonetary economic relations do not exist), or have considered that "Pareto optimality" is the goal to pursue rather than the fulfillment of, at least, everyone's basic needs. It is hardly surprising that we have a deficit of tools to readjust the economy to environmental constraints if economists use models in which the economy is a bootstrapped system decoupled from the planet in which it occurs. It is hardly surprising that we are not sure of the ways to downscale unsustainable sectors without triggering a recession, if recessions do not exist in general equilibrium models, and of course, the idea of a planned downscaling is unconceivable by mainstream economists. The relative lack of a solid economic foundation for recipes toward sustainability and equity is no reason for pessimism, if we note that the great majority of economists have simply worked in other directions. If we take advantage of the powerful scientific resources that we currently have at hand (which did not exist when the current main ideologies took their form), and we put them at work to find ways toward sustainability, equality and democracy, we will probably find ways toward sustainability, equality and democracy. This does not mean that everything that can be imagined is also feasible after investing enough time in research. As has been emphasized, we are subject to both environmental constraints and internal, dynamic constraints. I have focused on one likely constraint: that, probably, long-lasting complex systems can only occur midway between order and chaos (BOC). I explained that BOC is often associated with power laws and that part of the distribution of income inequality in capitalist societies does follow this distribution. Observations like this risk deriving into a naturalization of inequality, and a belief in that it is unavoidable. However, also, the law of gravity could make us think that flying is impossible, but precisely, the recognition that gravity exists and a good understanding of this force is a sine qua non condition to fly in planes and rockets without having many accidents. While this paper attempts to outline a scientific contribution to a sustainable and socially fair society and assumes that the scientific piece of the social transformation "jigsaw" is underdeveloped and badly needed, it pretends in no way to present the development of alternatives as an issue that belongs only to scientists. People who try to find alternatives based on their own paradigms of knowledge, scientific or not, and develop alternative experiences, also play an essential role. One thing that the BOC approach teaches us is that social transformation will not be fully planned, that some of its key features will have originated in the least expected corner and that the most reliable policies will have undergone a process of learning through the everyday interaction with realities that someone is trying to adapt to or to modify. Furthermore, the life of humans has extremely important aspects that are not easily quantifiable and amenable to scientific study. Social transformation also needs these aspects, but the ways to address them will not be scientific. Without changes also in these dimensions, we might never develop the collective will to push forward a policy addressed to a deep transformation of society, whether or not the recipe for this policy has been designed with the help of science. 


\section{Acknowledgments}

I am grateful to Laura Blanco Grau and Ester Conesa Carpintero for useful comments, to two anonymous reviewers for being so open-minded, to Ramon Margalef and Joan Martínez Alier, because their books were the main source of inspiration for my research, and to social movements, because, without them, works like this would be useless.

\section{Appendix}

\section{Indirectly Shaping the Income Distribution}

In a world with limited resources, an egalitarian distribution is essential for wellbeing. The conceptually simplest ways to ensure some level of equality are either detailed economic planning or severe constraints on income and wealth. However, if we reach a deep understanding of how the distributions of income and wealth emerge, we could find ways to optimize political interventions on the economy, in order to get much doing little (Section 6.3). We do not have this detailed knowledge, yet. However, here, I give some results from an income model that is too simple to be realistic, but that can convey one first impression of the potential of this approach.

Simple models in the literature assume that, among high income people, personal income follows a random walk (Section 3.2.1.). On average, the more money one has, the larger the amount of money one can invest, thus having higher odds of a large gain, but also of a large loss in case the investment fails. The variance $v$ in the changes in income $x$ per unit time can be assumed to have, roughly, the form:

$$
v(x)=a x^{\theta}
$$

with $a, \theta$ constants. Explicitly or implicitly, most studies assume $\theta=2$ (which Gibrat's law also attributes to firm sizes, Section 3.2.1.). Diversification of investments will favor a lower $\theta$. Consider the case of a large number of agents drifting at random, with no other rule than Equation (A1). In other words, for any income above some given threshold $x_{0}$, the chances of increasing or decreasing income are equal, and the variance of these changes follows Equation (A1). In addition, there is some entry of agents moving from $x<x_{0}$ to $x>x_{0}$, which compensates for the loss of agents, who, following their random walks, fall below $x_{0}$. The income distribution that results from this simple model is the power law

$$
f(x) \propto x^{-\theta}
$$

(as shown in [67] in a different context), which is realistic for large incomes, as discussed in Sections 3.1 and 3.2.1. This result has, in itself, some interesting implications. First, huge inequalities can arise without the need of any difference among agents, so it is not straightforward that inequalities should reflect differences in capacity (or even willingness) to compete in the market. Second, Equation (A2) has an infinite mean for $\theta \leq 2$, including Gibrat's case of $\theta=2$. What this means is that, strictly speaking, if $\theta \leq 2$, the distribution in Equation (A2) will never be found in practice, but we will observe an asymptotic convergence of the income distribution to Equation (A2). During this convergence, inequality will increase and the economy will grow. 
Now, let us consider a situation depicted in Section 6.3. On the one hand, there are limits to the aggregate income, because of the direct effect of resource scarcity, or because of policies limiting their use, or because demand does not grow (for example, because no advertising is allowed). On the other hand, there are policies giving a competitive advantage to activities performed by low-income people. Let us assume that these advantages operate below income $x_{0}$. Without limits to growth, the effect of the advantages alone would be to increase the flux of agents from $x<x_{0}$ to $x>x_{0}$, thus increasing the number of participants in the game, but without altering Equation (A2). However, if growth is limited, the increased income enjoyed by these new entrants will necessarily imply losses for other participants. Therefore, they will move from having equal chances to increase or decrease their income to having a larger chance of losing than gaining. One possibility is that, on average, income loss is proportional to current income. In this case, for $x>x_{0}$, the mean rate of change $\mu$ in income will have the form:

$$
\mu(x)=-b x
$$

with $b$ being a constant, $b>0$. More generally, $\mu$ could vary according to:

$$
\mu(x)=-b x^{\zeta}
$$

Equation (A4) with $\zeta>1$ would also result from a progressive tax: more progressiveness corresponds to larger $\zeta$ (in contrast, indirect taxes often translate to $\zeta<1$ ).

We can deduce the steady-state distribution that results in this situation by taking advantage of this general rule [210]:

$$
f(x) \propto v(x)^{-1} \exp \left(\int_{x_{0}}^{x} \frac{2 \mu(u)}{v(u)} d u\right)
$$

If we combine the simplest form of contraction (Equation (A3)) with the Gibrat exponent $\theta=2$ for Equation (A1) and we assume the same parameters for all people, Equation (A5) gives:

$$
f(x) \propto x^{-2\left(1+\frac{b}{a}\right)}
$$

More generally, Equation (A6) results from Equations (A1), (A4) and (A5) whenever $\theta-\zeta=1$. We still have a power law as in Equation (A2), but with a different exponent $\beta=2(1+b / a)$. The larger $b / a$, the lesser the fraction of the economy in the hands of the few richest people. The modification in parameter values causes a qualitative change if we cross the barrier from $\beta \geq 2$ to $\beta<2$, because we move from indefinite to limited growth, if the parameters remain constant through time. In practice, however, $\beta<2$ is often found in growing economies, because, most probably, the parameters change.

Whenever $\theta-\zeta \neq 1$, Equations (A1), (A4) and (A5) give:

$$
f(x) \propto x^{-\theta} \exp \left(-\frac{2 b}{a(\zeta-\theta+1)} x^{\zeta-\theta+1}\right)
$$

This is another qualitative change, because we move away from a strict power law. For incomes slightly or moderately above $x_{0}$, we still have the power law, but the shape of the high-income range changes. For $\theta-\zeta<1$, the upper tail becomes thinner (i.e., it converges quicker to $f(x)=0$ as $x$ increases), and the mean is finite, regardless of the exponent of the power law. As $\zeta$ increases and 
approaches $\theta$, what emerges is, effectively, an upper ceiling to income. For some given $\zeta$ and $\theta$, the ceiling will correspond to a lower income the larger the ratio of $b / a$. A large $b$ will result, for example, from an intensive promotion of the economic activities of low-income people, as mentioned. A large $b / a$ would also result from a small $a$, which is to be expected when moving from a high-profit and high-risk environment for investments to a more moderate situation. The proposals of interest-free collective credit in Section 6.3 could have this result.

The most problematic assumption is the equality of parameter values for all agents. However, the same equations can be applied in combination with a multivariate distribution for the parameters. Some useful predictions are feasible even in very complex situations. Even if the determinants of income are quite different from one person to another, rather than following a general model like this one, any factor that limits the mean income is most likely to produce an exponential decay in the tail of the distribution [79], which is equivalent to Equation (A7) with $\zeta \approx \theta$. As mentioned, this effectively results in a ceiling on income, and the position of this upper ceiling can be altered by processes taking place at the lower end of the distribution.

\section{Conflicts of Interest}

The author declares no conflicts of interest.

\section{References and Notes}

1. Martinez-Alier, J. Ecological Economics. In International Encyclopedia of the Social and Behavioral Sciences; Elsevier: Amsterdam, The Netherlands, 2013; p. 91008.

2. Mantegna, R.N.; Stanley, H.E. An Introduction to Econophysics: Correlations and Complexity in Finance; Cambridge University Press: Cambridge, UK, 2000.

3. Rickles, D. Econophysics for philosophers. Stud. Hist. Philos. Mod. Phys. 2007, 38, 948-978.

4. Chakraborti, A.; Muni Toke, I.; Patriarca, M.; Abergel, F. Econophysics review: I. Empirical facts. Quant. Financ. 2011, 11, 991-1012.

5. Chakraborti, A.; Muni Toke, I.; Patriarca, M.; Abergel, F. Econophysics review: II. Agent-based models. Quant. Financ. 2011, 11, 1013-1041.

6. Martinez-Alier, J.; Schlüpmann, K. Ecological Economics: Energy, Environment and Society; Blackwell: Oxford, UK, 1990.

7. Daly, H.E. Toward a Steady-State Economy; W. H. Freeman and Co.: San Francisco, CA, USA, 1973.

8. Riechmann, J. Otra forma de trabajar, producir y consumir: Los programas económicos de Die Grünen. Ecol. Política 1990, 6, 59-90.

9. Research \& Degrowth. Degrowth Declaration of the Paris 2008 conference. J. Clean. Prod. 2010, 18, 523-524.

10. Schneider, F.; Kallis, G.; Martinez-Alier, J. Crisis or opportunity? Economic degrowth for social equity and ecological sustainability. Introduction to this special issue. J. Clean. Prod. 2010, 18, 511-518.

11. Victor, P. Questioning economic growth. Nature 2010, 468, 370-371. 
12. Kallis, G.; Kerschner, C.; Martinez-Alier, J. The economics of degrowth. Ecol. Econ. 2012, 84, 172-180.

13. Lindley, M. J. C. Kumarappa. Mahatma Gandhi's Economist; Popular Prakashan: Mumbai, India, 2007.

14. Acosta, A. El Buen Vivir; Icaria: Barcelona, Spain, 2013.

15. Martinez-Alier, J. The Environmentalism of the Poor. A Study of Ecological Conflicts and Valuation; Edward Elgar: Cheltenham, UK, 2002.

16. Costanza, R.; Kubiszewski, I.; Giovannini, E.; Lovins, H.; McGlade, J.; Pickett, K.; Ragnarsdóttir, K.; Roberts, D.; de Vogli, R.; Wilkinson, R. Development: Time to leave GDP behind. Nature 2014, 505, 283-285.

17. Easterlin, R.A. Will raising the incomes of all increase the happiness of all? J. Econ. Behav. Organ. 1995, 27, 35-47.

18. Easterlin, R.A. Explaining happiness. Proc. Natl. Acad. Sci. USA 2003, 100, 11176-11183.

19. Sekulova, F.; van den Bergh, J.C.J.M. Climate change, income and happiness: An empirical study for Barcelona. Glob. Environ. Chang. 2013, 23, 1467-1475.

20. Edward, P. Examining inequality: Who really benefits from global growth? World Dev. 2006, 34, 1667-1695.

21. Goodland, R.; Daly, H. Why Northern income growth is not the solution to Southern poverty. Ecol. Econ. 1993, 8, 85-101.

22. Barro, R.; Sala-i-Martin, X. Economic Growth, 2nd. ed.; The MIT Press: Cambridge, MA, USA, 2004.

23. Georgescu-Roegen, N. The Entropy Law and the Economic Process; Harvard University Press: Cambridge, MA, USA, 1971.

24. Waldrop, M. Complexity. The Emerging Science at the Edge of Order and Chaos; Simon \& Schuster: New York, NY, USA, 1992.

25. Arthur, W.B. Complexity and the economy. Science 1999, 284, 107-109.

26. Delli Gatti, D.; Gaffeo, E.; Gallegati, M. Complex agent-based macroeconomics: A manifesto for a new paradigm. J. Econ. Interact. Coord. 2010, 5, 111-135.

27. May, R.M.; Levin, S.A.; Sugihara, G. Complex systems: Ecology for bankers. Nature 2008, 451, 893-895.

28. Haldane, A.G.; May, R.M. Systemic risk in banking ecosystems. Nature 2011, 469, 351-355.

29. Costanza, R.; Patten, B.C. Defining and predicting sustainability. Ecol. Econ. 1995, 15, 193-196.

30. Holling, C.S. Understanding the complexity of economic, ecological and social systems. Ecosystems 2001, 4, 390-405.

31. Pueyo, S. Irreversibility and Criticality in the Biosphere; University of Barcelona: Barcelona, Spain, 2003.

32. Ramos-Martin, J. Empiricism in ecological economics: A perspective from complex systems theory. Ecol. Econ. 2003, 46, 387-398.

33. Farell, K.N.; Winkler, R. Introduction. Ecol. Complex. 2006, 3, 65-274.

34. Norberg, J.; Cumming, G. Complexity Theory for a Sustainable Future; Columbia University Press: New York, NY, USA, 2008. 
35. Hallegate, S.; Hourcade, J.C.; Dumas, P. Why economic dynamics matter in assessing climate change damages: Illustration on extreme events. Ecol. Econ. 2007, 62, 330-340.

36. Heckbert, S.; Baynes, T.; Reeson, A. Agent-based modeling in ecological economics. Ann. N. Y. Acad. Sci. 2010, 1185, 39-53.

37. Bettencourt, L.; West, G. A unified theory of urban living. Nature 2010, 467, 912-913.

38. Vasileiadou, E.; Safarzyńska, K. Transitions: Taking complexity seriously. Futures 2010, 42, 1176-1186.

39. García-González, J. Degrowth and sustainability analyzed from the perspective of thermodynamics of irreversible processes. J. US-China Public Adm. 2011, 8, 1425-1436.

40. Espinosa, A.; Cardoso, P.P.; Arcaute, E.; Christensen, K. Complexity approaches to self-organisation: A case study from an Irish eco-village. Kybernetes 2011, 40, 536-558.

41. Wells, J. Complexity and Sustainability; Routledge: Oxon, UK, 2013.

42. Hock, D. Birth of the Chaordic Age; Berrett-Koehler: San Francisco, CA, USA, 1999.

43. Mandelbrot, B.B. The Fractal Geometry of Nature; W. H. Freeman and Co.: New York, NY, USA, 1983.

44. Pueyo, S. Is it a power law distribution? The case of economic contractions. 2013, arXiv:1310. 2567v1 [nlin.AO].

45. Peters, O.; Hertlein, C.; Christensen, K. A complexity view of rainfall. Phys. Rev. Lett. 2002, 88, 018701.

46. Main, I. Long odds on prediction. Nature 1997, 385, 19-20.

47. Guzetti, F.; Malamud, B.D.; Turcotte, D.L.; Reichenbach, P. Power-law correlation of landslide areas in Central Italy. Earth Planet. Sci. 2002, 195, 169-183.

48. Corral, A.; Ossó, A.; Llebot, E. Scaling of tropical-cyclone dissipation. Nat. Phys. 2010, 6, 693-696.

49. Malamud, B.D.; Morein, G.; Turcotte, D.L. Forest Fires: An Example of Self-Organized Critical Behavior. Science 1998, 281, 1840-1842.

50. Kadanoff, L.P. Statistical Physics: Statics, Dynamics and Renormalization; World Scientific: Singapore, 2000.

51. Solé, R.V. Phase Transitions; Princeton University Press: Princeton, NJ, USA, 2011.

52. Lenton, T.M. Environmental tipping points. Annu. Rev. Environ. Resour. 2013, 38, 1-29.

53. MacKay, G.; Jan, N. Forest fires as critical phenomena. J. Phys. A: Math. Gen. 1984, 17, L757-L760.

54. Packard, N. Adaptation Toward the Edge of Chaos; Technical Report CCSR-88-5; Center for Complex Systems Research, University of Illinois: Champaign-Urbana, IL, USA, 1988.

55. Langton, C.G. Computation at the edge of chaos: Phase transitions and emergent computation. Physica D 1990, 42, 12-37.

56. Kauffman, S.A.; Johnsen, S. Coevolution to the edge of chaos: Coupled fitness landscapes, poised states, and coevolutionary avalanches. J. Theor. Biol. 1991, 149, 467-505.

57. Meléndez, B. Paleontología; Paraninfo: Madrid, Spain, 1977; Volume 1.

58. Kirkpatrick, S.; Gelatt, C.D., Jr.; Vecchi, M.P. Optimization by simulated annealing. Science 1983, 220, 671-680. 
59. Klaus, A.; Yu, S.; Plenz, D. Statistical analyses support power law distributions found in neuronal avalanches. PLoS One 2011, 6, e19779.

60. Beggs, J.M.; Timme, N. Being critical of criticality in the brain. Front. Physiol. 2012, 3, doi:10.3389/fphys.2012.00163.

61. Kello, C.T.; Brown, G.D.A.; Ferrer-i-Cancho, R.; Holden, J.G.; Linkenkaer-Hansen, K.; Rhodes, T.; van Orden, G.C. Scaling laws in cognitive sciences. Trends Cogn. Sci. 2010, 14, 223-232.

62. Dehghani, N.; Hatsopoulos, N.G.; Haga, Z.D.; Parker, R.A.; Greger, B.; Halgren, E.; Cash, S.S.; Destexhe, A. Avalanche analysis from multielectrode ensemble recordings in cat, monkey, and human cerebral cortex during wakefulness and sleep. Front. Physiol. 2012, 3, doi:10.3389/ fphys.2012.00302.

63. Legenstein, R.; Maas, W. Edge of chaos and prediction of computational performance for neural circuit models. Neural Netw. 2007, 20, 323-334.

64. Miramontes, O.; Solé, R.V.; Goodwin, B.C. Neural networks as sources of chaotic motor activity in ants and how complexity develops at the social scale. Int. J. Bifurc. Chaos 2001, 11, 1655-1664.

65. Lovelock, J.E. The Ages of Gaia; W. W. Norton Co.: New York, NY, USA, 1988.

66. Loreau, M. From Populations to Ecosystems: Theoretical Foundations for a New Ecological Synthesis; Princeton University Press: Princeton, NJ, USA, 2010.

67. Pueyo, S. Diversity: Between neutrality and structure. Oikos 2006, 112, 392-405.

68. Margalef, R. Diversity and biodiversity-Their possible meaning in relation with the wish for sustainable development. An. Acad. Bras. Cienc. 1994, 66, 3-14.

69. Bak, P.; Tang, C.; Wiesenfeld, K. Self-organized criticality: An explanation for 1/f noise. Phys. Rev. Lett. 1987, 59, 381-384.

70. Bak, P. How Nature Works. The Science of Self-Organized Criticality; Copernicus: New York, NY, USA, 1996.

71. Pruessner, G. Self-Organised Criticality; Cambridge University Press: Cambridge, UK, 2012.

72. Pueyo, S. Self-organised criticality and the response of wildland fires to climate change. Clim. Chang. 2007, 82, 131-161.

73. Henley, C. Self-organized percolation: A simpler model. Bull. Am. Phys. Soc. 1989, 34, 838.

74. Drossel, B.; Schwabl, F. Self-organized critical forest-fire model. Phys. Rev. Lett. 1992, 69, $1629-1632$.

75. Pueyo, S.; Graça, P.M.L.A.; Barbosa, R.I.; Cots, R.; Cardona, E.; Fearnside, P. Testing for criticality in ecosystem dynamics: The case of Amazonian rainforest and savanna fire. Ecol. Lett. 2010, 13, 793-802.

76. Harris, T. The Theory of Branching Processes; Springer-Verlag: Berlin, Germany, 1963.

77. Pascual, M.; Guichard, F. Criticality and disturbance in spatial ecological systems. Trends Ecol. Evol. 2005, 20, 88-95.

78. Hubbell, S. The Unified Neutral Theory of Biodiversity and Biogeography; Princeton University Press: Princeton, NJ, USA, 2001. 
79. Pueyo, S.; He, F.; Zillio, T. The maximum entropy formalism and the idiosyncratic theory of biodiversity. Ecol. Lett. 2007, 10, 1017-1028.

80. Gabaix, X. Power laws in economics and finance. Annu. Rev. Econ. 2009, 1, 255-293.

81. Fujiwara, Y.; di Guilmi, C.; Aoyama, H.; Gallegati, M.; Souma, W. Do Pareto-Zipf and Gibrat laws hold true? An analysis with European firms. Physica A 2004, 335, 197-216.

82. Pareto, V. Cours d'Économie Politique Professé a l'Université de Lausanne; Rouge: Lausanne, Switzerland, 1897; Volume 2. (In French)

83. Yakovenko, V.M.; Rosser, J.B., Jr. Colloquium: Statistical mechanics of money, wealth, and income. Rev. Mod. Phys. 2009, 81, 1703-1725.

84. Latouche, S. L'autre Afrique: Entre don et marché; Albin Michel: Paris, France, 1998. (In French)

85. Zipf, G.K. Human Behavior and the Principle of Least Effort; Addison-Wesley Press: Oxford, UK, 1949.

86. Larrosa, M. Xarxa viària a la regió metropolitana de Barcelona. Un balanç. Papers: Regió Metropolitana de Barcelona 2003, 38, 63-85. (In Catalan)

87. Schweitzer, F.; Fagiolo, G.; Sornette, D.; Vega-Redondo, F.; Vespignani, A.; White, D.R. Economic networks: The new challenges. Science 2009, 325, 422-425.

88. Bauman, Z. Liquid Modernity; Polity Press: Cambridge, UK, 2000.

89. Mandelbrot, B.B. The variation of certain speculative prices. J. Bus. (Chic.) 1963, 36, 394-419.

90. Mantegna, R.N.; Stanley, H.E. Scaling behaviour in the dynamics of an economic index. Nature 1995, 376, 46-49.

91. Ormerod, P.; Mounfield, C. Power law distribution of the duration and magnitude of recessions in capitalist economies: Breakdown of scaling. Physica A 2001, 293, 573-582.

92. Stanley, M.H.R.; Amaral, L.A.N.; Buldyrev, S.V.; Havlin, S.; Leschhorn, H.; Maass, P.; Salinger, M.A.; Stanley, H.E. Scaling behaviour in the growth of companies. Nature 1996, 379, 804-806.

93. Amaral, L.A.N.; Buldyrev, S.V.; Havlin, S.; Leschhorn, H.; Maass, P.; Salinger, M.A.; Stanley, H.E.; Stanley, M.H.R. Scaling behavior in economics: I. Empirical results for company growth. J. Phys. I 1997, 7, 621-633.

94. Coad, A. A closer look at serial growth rate correlation. Rev. Ind. Organ. 2007, 31, 69-82.

95. Dosi, G.; Marsili, O.; Orsenigo, L.; Salvatore, R. Learning, market selection and the evolution of industrial structures. Small Bus. Econ. 1995, 7, 411-436.

96. Safarzyńska, K.; Frenken, K.; van den Bergh, J.C.J.M. Evolutionary theorizing and modeling of sustainability transitions. Res. Policy 2012, 41, 1011-1024.

97. Safarzyńska, K.; van den Bergh, J.C.J.M. Beyond replicator dynamics: Innovation-selection dynamics and optimal diversity. J. Econ. Behav. Organ. 2011, 78, 229-245.

98. Schumpeter, J.A. Capitalism, Socialism and Democracy; Harper \& Row: New York, NY, USA, 1942.

99. Champernowne, D.G. A model of income distribution. Econ. J. 1953, 63, 318-351.

100. Malcai, O.; Biham, O.; Richmond, P.; Solomon, S. Theoretical analysis and simulations of the generalized Lotka-Volterra model. Phys. Rev. E 2002, 66, 031102. 
101. Silva, A.C.; Yakovenko, V.M. Temporal evolution of the "thermal" and "superthermal" income classes in the USA during 1983-2001. Europhys. Lett. 2005, 69, 304-310.

102. Bak, P.; Chen, K.; Scheinkman, J.; Woodford, M. Aggregate fluctuations from independent sectoral shocks: Self-organized criticality in a model of production and inventory dynamics. Richerche Econ. 1993, 47, 3-30.

103. Scheinkman, J.A.; Woodford, M. Self-organized criticality and economic fluctuations. Am. Econ. Rev. 1994, 84, 417-421.

104. Krugman, P.R. The Self-Organizing Economy; Blackwell: Oxford, UK, 1996.

105. Thurner, S.; Klimek, P.; Hanel, R. Schumpeterian economic dynamics as a quantifiable model of evolution. New J. Phys. 2010, 12, 075029.

106. Xi, N.; Ormerod, P.; Wang, Y. Technological innovation, business cycles and self-organized criticality in market economies. Europhys. Lett. 2012, 97, 68005.

107. Podobnik, B.; Horvatic, D.; Petersen, A.M.; Urošević, B.; Stanley, H.E. Bankruptcy risk model and empirical tests. Proc. Natl. Acad. Sci. USA 2010, 107, 18325-18330.

108. Marx, K. Theorien über den Mehrwert, 1863. (In German)

109. Battiston, S.; Delli Gatti, D.; Gallegati, M.; Greenwald, B.; Stiglitz, J.E. Credit chains and bankruptcy propagation in production networks. J. Econ. Dyn. Control 2007, 31, 2061-2084.

110. Delli Gatti, D.; Gallegati, M.; Greenwald, B.C.; Russo, A.; Stiglitz, J.E. Business fluctuations and bankruptcy avalanches in an evolving network economy. J. Econ. Interact. Coord. 2009, 4, 195-212.

111. Fujiwara, Y.; Aoyama, H. Large-scale structure of a nation-wide production network. Eur. Phys. J. B 2010, 77, 565-580.

112. Loepfe, L.; Cabrales, A.; Sánchez, A. Towards a proper assignment of systemic risk: The combined roles of network topology and shock sharacteristics. PLoS One 2013, 8, e 77526.

113. Klimek, P.; Hausmann, R.; Thurner, S. Empirical confirmation of creative destruction from World trade data. PLoS One 2012, 7, e38924.

114. Schindler, M. Rumors in Financial Markets: Insights into Behavioral Finance; John Wiley \& Sons: Chichester, UK, 2007.

115. Keynes, J.M. The General Theory of Employment, Interest and Money; Macmillan: London, UK, 1936.

116. Ponzi, A.; Aizawa, Y. Evolutionary financial market models. Physica A 2000, 287, 507-523.

117. Cederman, L.E. Modeling the size of wars: From billiard balls to sandpiles. Am. Polit. Sci. Rev. 2003, 97, 135-150.

118. Fujiwara, Y. Omori law after large-scale destruction of production network. Prog. Theor. Phys. Suppl. 2012, 194, 158-164.

119. Hale, G. Bank relationships, business cycles, and financial crises. J. Int. Econ. 2012, 88, 312-325.

120. Daly, H.E. The perils of free trade. Sci. Am. 1993, 269, 50.

121. Minsky, H. Can “it” Happen Again?: Essays on Instability and Finance; M.E. Sharpe: Armonk, NY, USA, 1982.

122. McKay, A.; Reis, R. The brevity and violence of contractions and expansions. J. Monet. Econ. 2008, 55, 738-751. 
123. Gabaix, X. The granular origins of aggregate fluctuations. Econometrica 2011, 79, 733-772.

124. Bak, P.; Chen, K.; Tang, C. A forest-fire model and some thoughts on turbulence. Phys. Lett. A 1990, 147, 297-300.

125. Gould, J.D. Agricultural fluctuations and the English economy in the eighteenth century. J. Econ. Hist. 1962, 22, 313-333.

126. Petherick, A. Food and the future. Nat. Clim. Chang. 2011, 1, 91.

127. Brinkman, H.J.; de Pee, S.; Sanogo, I.; Subran, L.; Bloem, M.W. High food prices and the global financial crisis have reduced access to nutritious food and worsened nutritional status and health. J. Nutr. 2010, 140, 153S-161S.

128. Barriopedro, D.; Fischer, E.M.; Luterbacher, J.; Trigo, R.M.; García-Herrera, R. The hot summer of 2010: Redrawing the temperature record map of Europe. Science 2011, 332, 220-224.

129. Hansen, J.; Sato, M.; Ruedy, R. Perception of climate change. Proc. Natl. Acad. Sci. USA 2012, 109, E2415-E2423.

130. Dincer, I.; Rosen, M.A. Exergy: Energy, Environment and Sustainable Development, 2nd ed.; Elsevier: Oxford, UK, 2013.

131. Hall, C.A.S.; Balogh, S.; Murphy, D.J.R. What is the minimum EROI that a sustainable society must have? Energies 2009, 2, 25-47.

132. Hamilton, J.D. Oil and the macroeconomy. In The New Palgrave Dictionary of Economics Palgrave; Jiménez-Rodríguez, R., Sánchez, M., Eds.; Macmillan: London, UK, 2005; pp. 201-228.

133. IMF (International Monetary Fund). World Economic Outlook, April 2011; IMF: Washington, DC, USA, 2011.

134. Garrod, C. Statistical Mechanics and Thermodynamics; Oxford University Press: Oxford, $\mathrm{UK}, 1995$.

135. Nagy, B.; Farmer, J.D.; Bui, Q.M.; Trancik, J.E. Statistical basis for predicting technological progress. PLoS One 2013, 8, e52669.

136. Cleveland, C.J.; Costanza, R.; Hall, C.A.S.; Kaufmann, R. Energy and the US economy: A biophysical perspective. Science 1984, 225, 890-897.

137. Eide, A. The Right to Food and the Impact of Liquid Biofuels (Agrofuels); FAO: Rome, Italy, 2009.

138. Hubbert, M.K. The world's evolving energy system. Am. J. Phys. 1981, 49, 1007-1029.

139. Meadows, D.H.; Meadows, D.L.; Randers, J.; Behrens, W.W. The Limits to Growth; Universe Books: New York, NY, USA, 1972.

140. Hamilton, J.D. Causes and consequences of the oil shock of 2007-08. In Brookings Papers on Economic Activity: Spring 2009; Romer, D., Wolfers, J., Eds.; Brookings Institution: Washington, DC, USA, 2009; pp. 215-261.

141. Zhang, D.D.; Lee, H.F.; Wang, C.; Li, B.; Pei, Q.; Zhang, J.; An, Y. The causality analysis of climate change and large-scale human crisis. Proc. Natl. Acad. Sci. USA 2011, 108, 17296-17301.

142. Kerschner, C.; Prell, C.; Feng, K.; Hubacek, K. Economic vulnerability to Peak Oil. Glob. Environ. Chang. 2013, 23, 1424-1433.

143. Davis, S.J.; Haltiwanger, J. Sectoral job creation and destruction responses to oil price changes. J. Monet. Econ. 2001, 48, 465-512. 
144. Blinder, A.S.; Kilian, L. Comments and discussion. In Brookings Papers on Economic Activity: Spring 2009; Romer, D., Wolfers, J., Eds.; Brookings Institution: Washington, DC, USA, 2009; pp. 262-283.

145. Krugman, P. End this Depression Now! W. W. Norton: New York, NY, USA, 2012.

146. Campbell, C.J.; Laherrère, J.H. The end of cheap oil. Sci. Am. 1998, 278.3, 60-65.

147. Sorrell, S.; Speirs, J.; Bentley, R.; Brandt, A.; Miller, R. Global Oil Depletion-an Assessment of the Evidence for a Near-Term Peak in Global Oil Production; UK Energy Research Centre: London, UK, 2009.

148. IEA. World Energy Outlook 2011; OECD/IEA: Paris, France, 2011.

149. IEA. World Energy Outlook 2010; OECD/IEA: Paris, France, 2008.

150. Hughes, J.D. A reality check on the shale revolution. Nature 2013, 494, 307-308.

151. De Castro, C.; Miguel, L.J.; Mediavilla, M. The role of non conventional oil in the attenuation of peak oil. Energy Policy 2009, 37, 1825-1833.

152. Reynolds, D.B.; Kolodziej, M. Former Soviet Union oil production and GDP decline: Granger causality and the multi-cycle Hubbert curve. Energy Econ. 2008, 30, 271-289.

153. Wilkes, G. Strategies for Sustaining Crop Germplasm Preservation, Enhancement, and Use. Issues in Agriculture 5; Consultative Group on International Agricultural Research: Washington, DC, USA, 1992.

154. Cohen, M.L. Epidemiology of drug resistance: Implications for a post-antimicrobial era. Science 1992, 257, 1050-1055.

155. Goes, M.; Tuana, N.; Keller, K. The economics (or lack thereof) of aerosol geoengineering. Clim. Chang. 2011, 109, 719-744.

156. Sims, R.; Schock, R.; Adegbululgbe, A.; Fenhann, J.; Konstantinaviciute, I.; Moomaw, W.; Nimir, H.; Schlamadinger, B.; Torres-Martínez, J.; Turner, C.; et al. Energy supply. In Contribution of Working Group III to the Fourth Assessment Report of the Intergovernmental Panel on Climate Change; Metz, B., Davidson, O., Bosch, P., Dave, R., Meyer, L., Eds.; Cambridge University Press: Cambridge, UK, 2007; pp. 251-322.

157. Walker, J.; Cooper, M. Genealogies of resilience. From systems ecology to the political economy of crisis adaptation. Secur. Dialogue 2011, 42, 143-160.

158. Holling, C.S. Resilience and stability of ecological systems. Annu. Rev. Ecol. Syst. 1973, 4, $1-23$.

159. Nagy, B.; Farmer, J.D.; Trancik, J.E.; Gonzales, J.P. Superexponential long-term trends in information technology. Technol. Forecast. Soc. Chang. 2011, 78, 1356-1364.

160. Wiener, N. Cybernetics, or Control and Communication in the Animal and the Machine; Massachusetts Institute of Technology: Cambridge, MA, USA, 1948.

161. Langton, C.G. Editor's introduction. In Artificial Life; Langton, C.G., Ed.; Massachusetts Institute of Technology: Cambridge, MA, USA, 1995; pp. ix-xi.

162. Ray, T.S. An evolutionary approach to synthetic biology: Zen and the art of creating life. In Artificial Life; Langton, C.G., Ed.; Massachusetts Institute of Technology: Cambridge, MA, USA, 1995; pp. 179-209.

163. Margalef, R. Ecología; Omega: Barcelona, Spain, 1989. (In Spanish) 
164. Arthur, W.B. Increasing returns and the new world of business. Harv. Bus. Rev. 1995, 74, 100-109.

165. Travieso, G.; da Fontoura Costa, L. Spread of opinions and proportional voting. Phys. Rev. E 2006, 74, 036112.

166. Klimek, P.; Hanel, R.; Thurner, S. To how many politicians should government be left? Physica A 2009, 388, 3939-3947.

167. Litvinenko, A. Social media and perspectives of liquid democracy: The example of political communication in the Pirate Party in Germany. In Proceedings of the 12th European Conference on e-Government, Barcelona, Spain, 14-15 June 2012; Gasco, M., Ed.; Academic Publishing International Ltd.: Reading, UK, 2012; pp. 403-407.

168. Daly, H.E. The steady-state economy: Toward a political economy of biophysical equilibrium and moral growth. In Toward a Steady-State Economy; W. H. Freeman and Co.: San Francisco, CA, USA, 1973; pp. 149-174.

169. Daly, H.E. Steady-State Economics, 2nd ed.; Island Press: Washington, DC, USA, 1991.

170. Raventós, D. Basic Income: The Material Conditions of Freedom; Pluto Press: London, UK, 2007.

171. Johnson, W.A. The guaranteed income as an environmental measure. In Toward a Steady-State Economy; W. H. Freeman and Co.: San Francisco, CA, USA, 1973; pp. 149-174.

172. Research \& Degrowth. Degrowth Declaration Barcelona 2010. In Proceedings of the 2nd International Conference on Economic Degrowth for Ecological Sustainability and Social Equity, Barcelona, Spain, 26-29 March 2010.

173. Liegey, V.; Madelaine, S.; Ondet, C.; Veillot, A. Un Projet de Décroissance. Manifeste pour une Dotation Inconditionnelle d'Autonomie; Utopia: Paris, France, 2013. (In French)

174. Trigaux, R. The wealth repartition law in an altruistic society. Physica A 2005, 348, 453-464.

175. Moulaert, F.; Ailenei, O. Social economy, third sector and solidarity relations: A conceptual synthesis from history to present. Urban Stud. 2005, 42, 2037-2053.

176. Estivill Pascual, J.; Garcia Jané, J.; Valls Olivé, J.; Via Llop, J. Economia Solidària per a una Catalunya Lliure; Icaria: Barcelona, Spain, 2013. (In Catalan)

177. Pacione, M. Local Exchange Trading Systems as a response to the globalisation of capitalism. Urban Stud. 1997, 34, 1179-1199.

178. Proudhon, P.J. Textes Choisis, Présentés et Commentés par Joseph Lajugie: "Mutuellisme et Fédéralisme”; Dalloz: Paris, France, 1953. (In French)

179. Felber, C. Die Gemeinwohl-Ökonomie; Paul Zsolnay Verlag: Viena, Austria, 2010. (In German)

180. Roelants, B.; Dovgan, D.; Eum, H.; Terrasi, E. The Resilience of the Cooperative Model; CECOP-CICOPA: Brussels, Belgium, 2012.

181. Gulati, G.M.; Isaac, T.M.T.; Klein, W.A. When a workers' cooperative works: The case of Kerala Dinesh Beedi. UCLA Law Rev. 2002, 49, 1417-1454.

182. Dow, G.K.; Putterman, L. Why capital suppliers (usually) hire workers: What we know and what we need to know. J. Econ. Behav. Organ. 2000, 43, 319-336.

183. Asselain, J.C. La dynamique des inégalités de revenu en Yougoslavie. Rev. Etud. Comp. Est-O 1982, 13, 125-148. (In French) 
184. Daly, H.; Cobb, J.B.; Cobb, C.W. For the Common Good. Redirecting the Economy Towards Community, the Environment and Sustainable Future; Beacon Press: Boston, MA, US, 1989.

185. Castells, A. Les Col lectivitzacions a Barcelona: 1936-1939; Hacer: Barcelona, Spain, 1993. (In Catalan)

186. Gorostiza, S.; March, H.; Sauri, D. Servicing customers in revolutionary times: The experience of the collectivized Barcelona Water Company during the Spanish Civil War. Antipode 2013, 45, 908-925.

187. Ackerman, S. The Red and the Black. Available online: https://www.jacobinmag.com/2012/12/ the-red-and-the-black (accessed on 22 April 2014)

188. Wanberg, C.R. The individual experience of unemployment. Annu. Rev. Psychol. 2012, 63, 369-396.

189. Kallis, G.; Kalush, M.; O’Flynn, H.; Rossiter, J.; Ashford, N. "Friday off”: Reducing working hours in Europe. Sustainability 2013, 5, 1545-1567.

190. Sorman, A.H.; Giampietro, M. The energetic metabolism of societies and the degrowth paradigm: Analyzing biophysical constraints and realities. J. Clean. Prod. 2013, 38, 80-93.

191. Kallis, G. Societal metabolism, working hours and degrowth: A comment on Sorman and Giampietro. J. Clean. Prod. 2012, 38, 94-98.

192. Pueyo, S. L'atur té solució. Quaderns d'Illacrua 2012, 130, 1-3. (In Catalan)

193. Die Grünen. Gegen Arbeitslosigkeit und Sozialabbau. Sinvoll Arbeiten-Solidarisch Leben; Bundesgeschäftsstelle Die Grünen: Bonn, Germany, 1983. (In German)

194. Perkins, E.; Kuiper, E.; Quiroga-Martinez, R.; Turner, T.E.; Brownhill, L.S.; Mellor, M.; Todorova, Z.; Jochimsen, M.A.; McMahon, M. Exploring feminist ecological economics. Fem. Econ. 2005, 11, 107-150.

195. Martinez-Alier, J.; Munda, G.; O’Neill, J. Weak comparability of values as a foundation for ecological economics. Ecol. Econ. 1998, 26, 277-286.

196. Rosenberg, M.B. Nonviolent Communication. A Language of Life, 2nd ed.; PuddleDancer Press: Encinitas, CA, USA, 2003.

197. Sarkar, S. Una síntesis ecosocialista del problema de la sobrepoblación. Ecol. Política 1993, 6, 143-152. (In Spanish)

198. Milanovic, B. A short history of global inequality: The past two centuries. Explor. Econ. Hist. 2011, 48, 494-506.

199. Margalef, R. Teoría de los Sistemas Ecológicos; Universitat de Barcelona: Barcelona, Spain, 1991. (In Spanish)

200. Margalef, R. Our Biosphere; Ecology Institute: Oldendorf/Luhe, Germany, 1997.

201. Margalef, R. Progreso: una valoración subjetiva entusiasta de casi la mitad de los cambios en los sistemas vivos. In El Progreso ;Un Concepto Acabado o Emergente?; Wagensberg, J., Agustí, J., Eds.; Tusquests: Barcelona, Spain, 1998; pp. 169-192. (In Spanish)

202. Peltzer, D.A.; Wardle, D.A.; Allison, V.J.; Baisden, W.T.; Bardgett, R.D.; Chadwick, O.A.; Condron, L.M.; Parfitt, R.L.; Porder, S.; Richardson, S.J.; et al. Understanding ecosystem retrogression. Ecol. Monogr. 2010, 80, 509-529. 
203. Margalef, R. Life-forms of phytoplankton as survival alternatives in an unstable environment. Oceanol. Acta 1978, 1, 493-509.

204. May, R.M. Stability and Complexity in Model Ecosystems; Princeton University Press: Princeton, NJ, USA, 1973.

205. Jacobson, M.Z.; Delucchi, M.A. Providing all global energy with wind, water, and solar power, Part I: Technologies, energy resources, quantities and areas of infrastructure, and materials. Energy Policy 2011, 39, 1154-1169.

206. García-Olivares, A.; Ballabrera-Poy, J.; García-Ladona, E.; Turiel, A. A global renewable mix with proven technologies and common materials. Energy Policy 2012, 41, 561-574.

207. Mailand, M. The common European flexicurity principles: How a fragile consensus was reached. Eur. J. Ind. Relat. 2010, 16, 241-257.

208. Soddy, F. Wealth, Virtual Wealth, and Debt; Allen and Unwin: London, UK, 1961.

209. Henderson, N.; Sutherland, W.J. Two truths about discounting and their environmental consequences. Trends Ecol. Evol. 1996, 11, 527-528.

210. Engen, S.; Lande, R. Population dynamic models generating species abundance distributions of the gamma type. J. Theor. Biol. 1996, 178, 325-331.

(c) 2014 by the author; licensee MDPI, Basel, Switzerland. This article is an open access article distributed under the terms and conditions of the Creative Commons Attribution license (http://creativecommons.org/licenses/by/3.0/). 